\title{
Pampaneto, el monasterio de San Fructuoso y su influencia en la organización del valle riojano del río Leza, bajo la monarquía pamplonesa (siglos X y XI)*
}

Pampaneto, the monastery of the Saint Fructuoso and his influence in the organization of the Rioja valley of the river Leza, during the monarchy of Pamplona (10th and 11th centuries)

\author{
Serafín Olcoz Yanguas**
}

\begin{abstract}
RESUMEN
Al completar la revisión de la documentación albeldense de la época de Sancho Garcés III el Mayor (1004-1035)

se recupera la información conocida acerca del monasterio de pampanito y su influencia en la organización del valle del río Leza, desde su primeras noticias del siglo $X$, hasta su incorporación en el patrimonio albeldense $y$, finalmente, en el de San Prudencio de Monte Laturce, durante el reinado de García Sánchez III el de Nájera (1035-1054).
\end{abstract}

\section{PALABRAS CLAVE}

Reino de Pamplona, Pampaneto, San Fructuoso, reconquista de la Rioja, San Martín de Albelda, San Prudencio de Monte Laturce.

\section{ABSTRACT}

When the revision of the documents of Albelda during the kingdom of Sancho III the great $(1004-1035)$ was completed, the known information about the Monastry of Pampaneto and his influence in the organization of the river Leza is recovered, from his first news in the 10th century until his incorporation to the patrimony in Albelda, and finally to the one of Saint Prudencio of Mount Laturce, during the kingdom of García Sánchez III the one of Nájera ( 1035 - 1054 ).

\section{KEY WORDS}

Kingdom of Pamplona, Pampaneto, Saint Fructuoso, Reconquest of the Rioja, Saint Martin of Albelda, Saint Prudencio of Mount Laturce.

* Fecha de recepción del artículo: 2009-5-18. Fecha de aceptación del artículo: 2009-12-18.

** Universidad de Zaragoza. C.e.: olcoz@ unizar.es 


\section{INTRODUCCIÓN}

La última edición del cartulario del monasterio de San Martín de Tours, de Albelda (La Rioja), contiene sólo cinco documentos datados en la época del rey de Pamplona Sancho Garcés III. Tres de ellos tratan de donaciones que este monarca, junto su esposa Munia, realizaron a su maestro espiritual Leocario y que erróneamente se habían venido asociando con el monasterio albeldense ${ }^{1}$ pero que, en realidad, no tuvieron nada que ver con este cenobio riojano, sino que tratan acerca de diversas iglesias y monasterios situados en las cercanías de Pamplona, principalmente en el valle navarro de Garaño². Descartados estos tres documentos, los otros dos que quedan de la época de este monarca pamplonés hacen referencia, directa o indirectamente, al desaparecido monasterio riojano de Pampaneto ${ }^{3}$. De aquí el interés que motivó la revisión de lo que se conoce acerca de este monasterio riojano, desde sus oscuros orígenes hasta su final desvanecimiento entre los bienes del también desaparecido monasterio de San Prudencio de Monte Laturce (Clavijo, La Rioja).

Se comienza por explorar las primeras noticias conocidas acerca de Pampanito, así como su proceso expansivo e influencia en la repoblación y organización del valle del río Leza, de la que ya hay constancia entre mediados del siglo $\mathrm{X}$ y el momento de la ascensión al trono de Sancho Garcés III. Época que junto con la del reinado de este monarca pamplonés es en la que Pampaneto alcanzó su máximo esplendor, rivalizando con el que hasta entonces sólo había tenido y se le había reconocido al monasterio de Albelda en su influencia y control sobre la actual Rioja Media 4 .

Tanto es así, que Pampaneto llegó a hacerse con el control del valle riojano del río Leza incluyendo la rica vega que hay entre éste y su desembocadura en el río Ebro, proyectando así su labor de organización y apoyo en la primera línea de retaguardia. Esto es, en la región que propició la reconquista definitiva de Calahorra (La Rioja), en 1045, y el definitivo avance de la frontera entre la margen oriental del valle del Cidacos y la occidental del Alhama ${ }^{5}$.

\footnotetext{
1 La aclaración de la inexistencia de relaciones entre estos dos documentos de Sancho Garcés III y el cartulario albeldense también ha contribuido a la simplificación del problema existente acerca de la determinación de la advocación de este monasterio riojano y su posible evolución a lo largo de los siglos. Así como a tener que replantearse el proceso de expansión económica e ideológica y de control social que ejerció el monasterio de Albelda en el siglo XI, expuesto por Mercedes Lázaro, para poder atribuirle a este monasterio las pertenencias que le correspondían. GONZÁLEZ 1833, pp. VIII-IX, n. 218, UBIETO 1981, nn. 30-32 y LÁZARO 1997, pp. 356, 374-375 y 379-384.

2 Trabajo de Serafín Olcoz, titulado En Torno a la ubicación del castro Silbaniano y de la fortaleza de Sajrat Qais, en prensa.

3 UBIETO 1981, nn. 33-34.

4 Desafortunada e incomprensiblemente, García de Cortázar excluyó el valle del río Leza de su estudio sobre los comienzos de la ocupación y explotación cristiana de la Rioja Alta, en el período 903 y 1035. GARCÍA DE CORTÁZAR 1985, p. 310.

5 Nueva frontera que se inmovilizó hasta que en 1119 la reactivó Alfonso I el Batallador(1104-1134), tras reconquistar las ciudades de Zaragoza (Aragón) y Tudela (Navarra) para su reino de Aragón y Pamplona.
} 
La posterior restauración de la sede episcopal calagurritana, de origen hispanoromano, no conllevó la instalación en esta ciudad riojana del que hasta entonces era obispo de Nájera, ya que éste decidió presidir la comunidad monástica del monasterio albeldense con la ayuda de un prior e, incluso, residir intermitentemente en el monasterio albeldense, desde poco después de la reconquista de Calahorra ${ }^{6}$. Sin duda, esta decisión de contar con una sede episcopal itinerante contrasta con los objetivos reales perseguidos con la fundación del monasterio o, mejor dicho, colegiata de Nájera, en $1052^{7}$, pudiendo estar relacionada con los conflictos debidos a la reorganización del territorio que por entonces llevó a cabo García Sánchez III y que también provocó la incorporación de Pampaneto entre las propiedades del floreciente monasterio albeldense, a cambio de recuperar para la corona pamplonesa un mayor control sobre la rica vega del Ebro y la vía de comunicaciones más importante entre la retaguardia riojana y la nueva vanguardia calagurritana.

Poco a poco, el asentamiento de la nueva frontera sudoriental conllevó el creciente control señorial sobre esta comarca pamplonesa, y condujo también a una reorganización general del territorio, y en particular del que hasta entonces había estado bajo el dominio e influencia del monasterio albeldense. Particularmente tras la derrota de Atapuerca (Burgos), que provocó el cambio en el gobierno del reino de Pamplona y, con él, importantes transformaciones.

Sin duda, una de las decisiones que tuvo mayor trascendencia para la Rioja Media y que se cuenta entre las más destacadas de Sancho Garcés IV el de Peñalén (1054-1076) fue la de apoyarse en el desarrollo de la influencia ejercida por sus parientes, los Fortuñones que, entre otras actividades, también se materializó en la escisión del monasterio de San Prudencio de Monte Laturce del control albeldense. A partir de este momento, el monasterio de San Prudencio de Monte Laturce se convirtió en el foco cultural y político con mayor influencia en los valles riojanos del Leza y del Cidacos, bajo el patronato señorial de los Fortuñones, relegando al monasterio de San Martín de Tours de Albelda ${ }^{8}$ a una posición secundaria, cuya influencia se mantuvo principalmente en el valle del Iregua, aunque sólo como el preludio de su posterior y definitiva decadencia.

6 Luis Javier Fortún analizó la configuración del sistema de los obispos-abades bajo el reinado de Sancho Garcés III y su continuación bajo el de García Sánchez III, identificando a los obispos de Nájera que también asumieron el cargo de abad del monasterio de San Millán de la Cogolla. Sin embargo, en el caso del obispo Gomesando (1046-1065), aunque dejó de estar directamente al frente del monasterio emilianense, tras nombrar un abad en 1047, e indirectamente incluso, al ser sustituido en estas funciones por el obispo de Álava, entre 1053-1055, y de nombrar un nuevo abad emilianense en 1057, siguió estando a cargo del albeldense de forma continuada, entre 1048, al menos, y el final de sus días. SÁlNZ 1994, pp. 220-221 y FORTÚN 2005, pp. 215-217, 223-225 y 230-231.

7 Margarita Cantera señaló que su construcción se inició en 1052, consagrándose la iglesia, que no monasterio, en el mes de diciembre. CANTERA 2005, pp. 48 y 51.

8 Margarita Cantera destacó la importancia que alcanzó este monasterio dedicado a San Martín de Tours cuando sólo medio siglo después de su fundación su comunidad estaba compuesta por 200 monjes. Sin embargo, creyó que su declive comenzó algo más tarde de lo que en realidad lo hizo, pues lo achacó a la incorporación de La Rioja a Castilla, en 1076. CANTERA 1985, p. 56. 
Esta segunda gran reorganización territorial de la Rioja Media también supuso el declive definitivo del monasterio de Pampaneto, que acabó siendo incorporado al monasterio de San Prudencio de Monte Laturce y entre cuyas propiedades acabó diluyéndose su casi perdida memoria ${ }^{9}$.

Finalmente, cabe añadir que con la exploración de la trayectoria histórica de Pampaneto concluye la revisión de la documentación conservada en el cartulario albeldense de la época de Sancho Garcés III y el objetivo que inicialmente se perseguía. No sin destacar que también se desea llamar la atención sobre la necesidad de estudiar el devenir de esta región pamplonesa, durante los siglos X y XI, con mayor profundidad de lo que hasta ahora se ha venido haciendo.

\section{LAS PRIMERAS NOTICIAS DE PAMPANETO}

Al tratar acerca del topónimo riojano y tardoantiguo de Parpalines (Pipaona de Ocón), en la Rioja Media, Santiago Castellanos propuso que, aunque su morfología era distinta, debería relacionarse con el monasterio conocido como Pampaneto ${ }^{10} y$, de pasada, hizo un escueta enumeración de las referencias albeldenses y del monasterio de San Prudencio de Monte Laturce que estricta y directamente hacían referencia al conocido como Pampaneto ${ }^{11}$. Pudiendo considerarse esta recapitulación como la única y más completa revisión que se ha realizado acerca de la historia de este monasterio, casi olvidado.

Se desconoce el momento de la fundación de Pampaneto, pero es muy probable que fuese realizada por Sancho Garcés I (905-925) en las mismas fechas en las que éste restauró el monasterio albeldense, tras la victoriosa campaña del año 923, y que, como en este caso, tampoco se tratase de una fundación, sino de la restauración de un monasterio visigodo preexistente ${ }^{12}$.

9 Cabe destacar que gran parte de la documentación relacionada con Pampaneto y, por tanto, una pequeña pero importante parte de la que hace referencia a los monasterios de Albelda y de San Prudencio de Monte Laturce, se ha conservado hasta nuestros días tras haber sido muy manipulada. Por lo que también se ha creído interesante intentar acotar en qué momento se produjeron las interpolaciones, reconstrucciones o invenciones de estos documentos. Con lo que no sólo se contribuye a una mayor comprensión y un mejor alcance de la información que aporta esta documentación sino que, con su detallada revisión, también se contribuye a esclarecer la advocación e historia del monasterio albeldense que, hasta ahora, estaba sumida en una gran oscuridad.

10 Santiago Castellanos planteó la posibilidad de que Parpalines hubiese estado en Pipaona de Ocón o bien en Ojacastro, en la Rioja Alta, decantándose por la zona de Ocón y Pipaona, en el valle del río Leza. Posteriormente, Urbano Espinosa identificó restos arqueológicos que constatan la ocupación continua, entre los siglos I/II d. C. y la Plena Edad Media, en el término de Parpalinas, que previamente había identificado con el de Parpalines, ubicándolo en las cercanías de la villa riojana de Pipaona de Ocón, en un punto casi equidistante entre las poblaciones riojanas de Varea (Varea, Logroño) y Calahorra. CASTELLANOS 1995, pp. 36-37, ESPINOSA 2003, pp. 85-88 y ESPINOSA 2006, 309-312.

11 Santiago Castellanos enumeró los documentos relacionados con el monasterio de Pampaneto que habían sido publicados por Antonio Ubieto en el cartulario albeldense y por García Turza en el de San Prudencio de Monte Laturce. UBIETO 1981, nn. 8, 29, 33 y 35-37, GARCÍA 1992, n. 10 y CASTELLANOS 1995, p. 37.

12 Julián Cantera aventuró la posibilidad de un origen visigodo del monasterio albeldense. CANTERA 1950a, pp. 19-23. 
La primera de estas noticias data del año 941, y hace referencia a la donación que el monarca pamplonés, sucesor y heredero de aquél, García Sánchez I (925970) $)^{13}$, hizo al monasterio al que llamaban Pampaneto del lugar que allí mismo se conocía como Senzano ${ }^{14}$, lo que permite conocer su ubicación ${ }^{15}$, y de cierta tierra en Matrec ${ }^{16}$, así como de otra de Billiti ${ }^{17} \mathrm{lbn}$ Muza; concretando que la transacción fue realizada en el monasterio o atrio de San Román ${ }^{18}$, y que el rey la hizo para que éste le fuese propicio ${ }^{19}$.

Es interesante destacar que entre los confirmantes de esta donación figuran los tenentes de las dos tenencias riojanas más importantes y cercanas a Pampaneto, Flaín Bermúdez en Viguera (La Rioja) ${ }^{20}$ y Mango Aznárez en Jubera (Santa En-

13 GOVANTES 1846, p. 168 y UBIETO 1981, n. 8.

14 En 2007, la actual aldea de Zenzano, perteneciente al municipio de Lagunilla de Jubera (La Rioja) desde 1975, contaba con una población de 15 habitantes. Zenzano está ubicado en la vertiente meridional del monte Zenzano, junto a un barranco que desemboca por la margen izquierda del arroyo Bahún, siendo éste, a su vez, un afluente por la margen izquierda, también, del río Jubera. El cual, finalmente, desemboca en el río Leza, en Murillo del Río Leza (La Rioja), poco antes de que éste desemboque en el Ebro, en Agoncillo (La Rioja).

${ }_{15} \mathrm{M}^{\text {a }}$ Concepción Fernández de la Pradilla y Margarita Cantera ubicaron Pampaneto cerca de Zenzano y de Villanueva de San Prudencio, sin caer en la cuenta de que esta villa se fundó en el propio término o coto de Pampaneto, como se ve más adelante. Además, Cantera creyó que Pampaneto se había fundado poco antes de su incorporación al monasterio de Albelda, en 1048, sin tener en cuenta la existencia de documentación de Pampaneto de mediados del siglo X; dato que tampoco tuvo en cuenta García Turza cuando localizó Pampaneto en tierras de Ocón (La Rioja). Por otra parte, Cantera también recogió su posterior incorporación al monasterio de San Prudencio de Monte Laturce; además, y como Mercedes Lázaro, creyó que la del mártir oriental San Román, diácono mártir de Antioquia (Tierra Santa), fue una de las múltiples y difícilmente explicables advocaciones que tuvo Pampaneto. CANTERA 1985, pp. 49 y 51, GARCÍA 1989, pp. 145-146, GARCÍA 1992, p. 18 y 235, FERNÁNDEZ DE LA PRADILLA 1994, p. 36, LÁZARO 1997, p. 356 y GRANADO Y FERNÁNDEZ DE LA PRADILLA 1999, p. 16.

${ }_{16}$ Madriz es partido judicial de Nájera (La Rioja), según Ubieto que, como García Turza, completó la información ofrecida por Govantes acerca de la comunidad de pastos que el monasterio de Valvanera (Anguiano) compartía con otras localidades riojanas entre las que se encontraba Madriz además de Anguiano, Tobía, Matute, Villanueva y Ojacastro. Previamente, Joaquín Peña había concretado que el concejo de Matriz estuvo formado por los pueblos riojanos de Berceo, Estollo, San Andrés del Valle, actualmente incluido en Estollo, y San Miguel del Llano y Barrio-Espaso que hoy es una prolongación de Berceo. Constando que, en 1029, la villa de Madriz había sido donada al monasterio de San Millán de la Cogolla. Sin embargo, podría tratarse del despoblado de Matres, ubicado en las cercanías de Logroño y que Julián Cantera localizó gracias a la pervivencia de topónimo de Puente Madre, en la margen izquierda del río Iregua. GOVANTES 1846, pp. 13, 64, 167-168, 201 y 259, CANTERA 1958, p. 318, PEÑA 1959, p. 82, UBIETO 1976, n. 192, UBIETO 1981, p. 113, GARCÍA 1993, p. 235 y FERNÁNDEZ DE LA PRADILLA 1994, p. 42.

17 Esta lectura es confusa, pudiendo también tratarse de Nath y, en cualquier caso, no se puede decir más acerca de su localización.

18 El monasterio de San Román pudiera estar a cargo del presbítero Sancho y de su hermano Blasco. Además, dado que figura todo el concilio de Jubera, bien pudiera hallarse este cenobio en un término que también perteneciese a su dominio y quizá pudiera tratarse de San Román de Cameros (La Rioja), en la orilla izquierda del río Leza, si en aquella época dependía de Jubera. GOVANTES 1846, pp. 173-174.

${ }_{19}$... ad monasterio qui vocatur Pampaneto in atrio Sancti Romani, qui michit sit propitio; trado ibidem locum quod dicitur Senzano et terra in Matrec ad quator modios seminatura, ut sit ex Domino vel de me donatum vel confirmatum, et alia terra de Billit Iben Muza. UBIETO 1981, n. 8.

20 Flaín, Laín o Flavio Bermúdez, de probable origen castellano o alavés, fue uno de los nobles destacados en la corte de Ordoño II (914-924), rey de León, que estuvo a cargo de la estratégica ciudad de Viguera, documentado entre el año 941, aunque puede que lo fuese desde el año 923, y el 947. LEZA 1959, p. 8, VICUÑA 1971, pp. 128 y 131 y UBIETO 1981, nn. 8 y 16. 
gracia de Jubera, La Rioja) ${ }^{21}$, y entre los testigos García Iñiguez de Gallipienzo (Navarra), Blasco Domínguez, el presbítero Valentino, Sancho Iñiguez, Iñigo Sánchez, Munio Álvarez, Dulquito y Maruán de Leza (Leza de Río Leza, La Rioja), el presbítero Sancho y su hermano Blasco, así como todo el concilio de Jubera y muchos otros hombres buenos y principales. De esta última información se deduce que entonces Pampaneto y Zenzano dependían administrativamente de la importante tenencia fronteriza de Jubera, encontrándose en su extremo sudoccidental y limítrofe con la de Viguera. Aunque también es un indicio del carácter apócrifo de este documento y de las reservas que deben tenerse a la hora de considerar el contexto histórico de este documento.

\section{PAMPANETO EN LA SEGUNDA MITAD DEL SIGLO X}

La segunda y última noticia acerca de Pampaneto en el siglo $X$ se corresponde con la confirmación que de la anterior donación de García Sánchez I hicieron, el 6 de mayo del año 985, estando en la ciudad de Viguera, su hijo y heredero como rey de Pamplona, Sancho Garcés II Abarca (970-994), su esposa, la reina Urraca Fernández, y sus hijos García Sánchez II el Temblón (994-1000), Ramiro y Gonzalo.

En este documento no se cita expresamente a Pampaneto y tan sólo indica que confirmamos hanc donationem quam dedi[t] pater noster domnus Garsea rex, cui tributa Deus veniam, ad ipsum supradictum monasterium et sanctorum Cosme et Damiani, pro animabas nostris, ita ut habeamus partem in intercessione sanctorum ipsorum et sancti Romani2 vuel in oraciones et sacrificis que ibidem offeruntur regi prolorum, amen.

Sin embargo, como en las copias del siglo XVI que se conservan tanto de este documento como del anterior, ambas van seguidas, se puede suponer que el copista renacentista era conocedor de su relación ${ }^{23}$. La referencia a San Cosme y San Damián ${ }^{24}$ se debe a que el documento fue expedido en Viguera, donde se encontraba el monasterio en honor a dichos santos, que también acabó siendo incorporado al monasterio albeldense ${ }^{25}$. Mientras que la de San Román, segura-

${ }^{21}$ M. ${ }^{\text {a }}$ Concepción Fernández de la Pradilla e Ignacio Granado también recogieron a los dos primeros tenentes que se conocen de Viguera y de Jubera, como antecedentes de los orígenes del señorío de Cameros, así como, en general, de La Rioja. FERNÁNDEZ DE LA PRADILLA 1994, p. 36 y GRANADO y FERNÁNDEZ DE LA PRADILLA 1999, p. 16.

22 Julián Cantera interpretó, erróneamente, mozlesmes (musulmanes) como si se tratara del nombre de un lugar en cuyas pertenencias se instauró el culto a San Cosme y San Damián, así como a San Román. CANTERA 1962, p. 334.

23 Ubieto no justificó el encabezamiento que añadió a este documento pero su razonamiento no debió ser muy diferente del expuesto. UBIETO 1981, n. 29.

24 Tomás González y Goñi Gaztambide atribuyeron a estos santos la advocación del monasterio de Pampaneto. GONZÁLEZ 1833, p. VIII, n. 217 y GOÑI 1979, p. 108.

25 En 1072, Sancho Garcés IV donó a Iñigo Aznarez, señor de Viguera (1063-1076) y de otras tenencias pamplonesas, el monasterio de San Cosme y San Damián, que hubo en Viguera, concretamente subtus Vekaria, con la condición de que después pasase al monasterio de San Martín de Albelda. En 1074, este monasterio de San Cosme y San Damián, recibió sendas donaciones de Sancho Garcés IV, 
mente, se debe a que en su monasterio fue donde se había expedido el documento que entonces se confirmó.

En esta ocasión se cita como testigo de la donación al que debía ser el abad de Pampaneto, Rapinatus, junto a los obispos Benedicto (970-985) de Nájera ${ }^{26}$ y Julián (983-987) de Pamplona ${ }^{27}$; a los abades de sendos monasterios, Velázquez y Moguera, siendo también este último juez; a los señores Jimeno y Abeiz y a toda la milicia del palacio del rey Sancho Garcés II, a los que se añadió la confirmación de Iñigo García.

Aunque en el escatocolo de este documento no se citan las advocaciones de los dos monasterios cuyos abades acompañaron al de Pampaneto en este acto solemne, cabría plantear la posibilidad de que uno de ellos pudiera tratarse del monasterio de San Cosme y San Damián, y que el otro fuese el de San Román. Lo que podría ser indicativo de la existencia de una relación, e incluso de cierta dependencia jerárquica que, de haberse dado, pudo tener comienzo a mediados de siglo, como resultado de la amenaza de los ataques musulmanes que forzaron la incorporación del monasterio de Celanova, la iglesia de San Vicente ${ }^{28}$ y la basílica en la que se encontraban las reliquias de San Prudencio $^{29}$, en la peña o monte Laturce, al de San Martín de Albelda ${ }^{30}$.

una en solitario y otra con su esposa Placencia. Dado el interés mostrado por la monarquía pamplonesa en consolidar el coto redondo del monasterio albeldense en el valle del Iregua, pocos años antes, concretamente, en 931, como destacó Mercedes Lázaro, habría que suponer que este monasterio de San Cosme y San Damián, bajo Viguera, quedaba fuera de él, ya que ésta estaba en el límite meridional del monasterio albeldense, como señaló Cantera Orive, y que, además, correspondía al límite occidental del territorio en el que ejercía su influencia el de Pampaneto. Cantera Montenegro sólo recogió la advocación de estos santos sanadores en el monasterio dedicado a ellos que hubo en Viguera y que dependía del albeldense, como así consta en el inventario del prior Mirón. CANTERA 1950b, pp. 323-324, CANTERA 1950c, p. 510, UBIETO 1973, p. 229, UBIETO 1981, nn. 57, 59-60 y 68, SÁINZ 1981, nn. 7-8, CANTERA 1985, p. 53, FERNÁNDEZ DE LA PRADILLA 1991, p. 268 y LÁZARO 1997, pp. 369, 371 y 380.

26 SÁINZ 1981, pp. 191-196.

27 GOÑI 1979, pp. 107-109.

${ }_{28}$ Cabría la posibilidad de considerar la iglesia de San Vicente como un lugar distinto del que albergó a la basílica que acabó siendo el monasterio de San Prudencio de Monte Laturce. De ser así, quizá se podría ubicar dicha iglesia de San Vicente en la desaparecida aldea de Yangüela (Logroño), cerca de Alberite (La Rioja), en la que Margarita Cantera localizó una iglesia de San Vicente que, además, acabó siendo incorporada al monasterio de San Prudencio por el rey de Castilla y León, Alfonso VII el Emperador (11261157). Aunque también podría tratarse de otro San Vicente cuyo topónimo se conserva en Murillo del Río Leza, algo más al norte de la desembocadura del Jubera en el Leza. CANTERA 1985, p. 49.

${ }_{29}$ García Turza señaló la relación existente con el obispo de Tarazona, Prudencio de Armentia (Condado de Treviño, Burgos), que vivió en el siglo VI y cuyos restos mortales fueron sepultados en la iglesia cuya primitiva advocación era la de San Vicente. Además expuso las tradiciones historiográficas relativas a los orígenes de este monasterio que, según él, hay constancia documental de que pasó a ser conocido como el monasterio de San Prudencio a principios del siglo XI. Identificando la segunda etapa de este monasterio con la de su dependencia del albeldense, entre los años 950 y 1058 . Además, García Turza expuso la controversia existente en la historiografía acerca de la antigüedad e importancia de San Prudencio, aquí citado como señor Prudencio. Sin embargo, Margarita Cantera ya había aclarado que no hay diferencia entre señor y San Prudencio pues, en otros documentos del cartulario albeldense, a San Martín se le cita como señor Martín. CANTERA 1951b, p. 534, SÁINZ 1981, n. 3, FERNÁNDEZ DE LA PRADILLA 1991, p. 268, GARCÍA 1992, pp. 15-16 y CANTERA 1985, pp. 50-51.

30 Mercedes Lázaro también recogió la reorganización de estos monasterios que se incorporaron al monasterio albeldense a mediados del siglo X. Además, propuso la localización de la villa de Bagibel al 
En cualquier caso, es posible plantear una redefinición del proceso de control del espacio, del aprovechamiento económico y de la repoblación en la Rioja Media desde poco antes de mediados del siglo $X$ hasta finales de éste, en el que Pampaneto surge como un tercer foco religioso y político con el que se estructuró administrativamente y se fijó la población en el avanzado valle del río Leza. Foco que habría que añadir a los consabidos de Nájera y San Millán (San Millán de la Cogolla), en el valle del río Najerilla, así como el de Albelda, en el del río Iregua ${ }^{31}$. Sin olvidar el monasterio de San Cosme y San Damián, también en este valle, así como el de San Román en el del río Leza, entre otros, cuya historia convendría recuperar y que también habría que tener en cuenta a la hora de tener una visión panorámica de la organización de la Rioja Media en los siglos X y XI.

\section{PAMPANETO EN ÉPOCA DE SANCHO GARCÉS III}

La siguiente noticia conocida referente a Pampaneto data del año 1032 y aclara su advocación a San Fructuoso ${ }^{32}$, así como también parece informar acerca de su tipología como eremitorio, ya que lo califica como arcisterio. Además, en esta ocasión y supuestamente, Sancho Garcés III añadió información acerca de que, previamente, él mismo había dado lugar a la fundación de la población de Villanova (Villanueva de San Prudencio, Lagunilla de Jubera) ${ }^{33}$ y le había asignado un coto redondo a esta villa en illis terminis prenominatis Restagim, deinde a parte quoque, deinde ad illos molinos de Patrerne, deinde ad fontem Abrahan ${ }^{34}$, deinde a Molar-

sur de San Román de Cameros, entre ésta y Hornillos de Cameros. Lo que supondría la extensión de los dominios albeldenses al sur de los de Pampaneto, hacia el nacimiento del río Leza. LÁZARO 1997, p. 372

31 Mercedes Lázaro señaló el destacado papel desempeñado por el obispado de Nájera y el monasterio de San Martín de Albelda en esta época, acorde con el avance y control progresivo hacia la frontera de la Marca Superior. LÁZARO 1997, pp. 368-372.

${ }_{32}$ Margarita Cantera, a quien siguió M. ${ }^{a}$ Concepción Fernández de la Pradilla, identificó esta advocación con la del homónimo obispo de Tarragona que allí fue martirizado el año 259, en la persecución del emperador Valeriano (253-260). CANTERA 1985, p. 49 y FERNÁNDEZ DE LA PRADILLA 1991, p. 268.

${ }^{33}$ En el documento consta que Sancho Garcés III iussimus fieri hanc paginolam propter populationem quam fecimus in vita nostra in arcisterium Sancti Fructuosi quod dicitur Pampaneto, et fecimus hanc populationem pro remedium anime nostre in locum quod dicitur Villanova. La actual aldea de Villanueva de San Prudencio está ubicada en las cercanías de Zenzano, sólo que en la vertiente del río Leza en lugar de la de su afluente por la margen derecha, el río Jubera. De hecho, se encuentra junto a un barranco que desemboca por la margen derecha del arroyo de Mudarra, siendo éste, a su vez, un afluente por la margen derecha, también, del río Leza. Como señaló Govantes, esta villa, antiguamente, se llamó Villanova de Pampaneto. Fernández de la Pradilla sólo pudo decir que el monasterio de San Fructuoso estuvo entre Villanueva de San Prudencio y Zenzano. Por su parte, Felipe Abad incluyó entre las posibles iglesias y monasterios riojanos de posible origen eremítico a Villanueva de San Prudencio, ubicándola cerca de Zenzano a la vez que, a continuación y como un monasterio distinto, citó al de San Fructuoso de Pampaneto, ubicándolo en Zenzano y creyendo erróneamente que su primera referencia documentada databa de 1032. GOVANTES 1846, p. 212, UBIETO 1981, n. 33, FERNÁNDEZ DE LA PRADILLA 1991 , p. 268 y ABAD 1999, p. 310.

${ }_{34}$ Podría tratarse de la actual Peña Rubia de Leza de Río Leza, al norte de Villanueva de San Prudencio. 
tum, deinde ad illo Lavaco, deinde ad Sierra de Vento ${ }^{35}$, deinde a Penna Amarilla ${ }^{36}$ Hii sunt terminos qui apertinent ad Sancti Fructuosi sive exemptis. Añadiendo las obligaciones a las que debía someterse la población que allí se asentara, y que modificó con otras condiciones a las que debían sujetarse ${ }^{37}$ con respecto al abad de San Fructuoso, o a quien lo rigiera ${ }^{38}$.

Desafortunadamente, el escatocolo de este documento presenta graves inconsistencias, ya que Sancho Garcés III figura como rex in Aragone et in Pampilona et in Castella et in Campis vel in Legione imperiali culmine ${ }^{39}$. De modo que aunque los confirmantes, el obispo Sancho de Pamplona (1024-1052) ${ }^{40}$ y el obispo Poncio de Oviedo (1025-1028) ${ }^{41}$, junto con los testigos, los dos señores homónimos Fortún Sánchez ${ }^{42}$ y el señor Fortún Ochoaz ${ }^{43}$, podrían corresponder a un

35 Podría tratarse de la actual Sierra de Hayedo, que hace de límite entre Leza de Río Leza y Villanueva de San Prudencio, al noroeste de ésta.

${ }^{36}$ Podría tratarse de la actual Fuente de Santa Cecilia, al sur de Villanueva de San Prudencio. De ser así, este coto redondo podría corresponder con los términos de Zenzano y Villanueva de San Prudencio juntos.

${ }_{37}$ Mercedes Lázaro señaló este cambio en las condiciones al indicar que, inicialmente, la monarquía concedió cartas repobladoras, que casi siempre contenían prerrogativas de inmunidad e ingenuidad extensibles a los nuevos moradores, de modo que nadie pudiera reclamar derechos sobre ellos: "qui non habeant aliud pondus, nec alium pactum». Mientras que, a partir de este momento, esto es, del año 1032 y por voluntad expresa de la monarquía pamplonesa, es el monasterio de Pampaneto el que asumió esta responsabilidad de repoblación. A pesar de que la exposición de Lázaro parece indicar que quien asumió dicha responsabilidad fue el monasterio albeldense hay que recordar que en dicha época, el de San Fructuoso o Pampaneto todavía no dependía de él sino que aún era independiente. LÁZARO 1997, pp. 375376.

38 A diferencia de lo que creyó Ubieto, a quien siguieron Roldán Jimeno y Aitor Pescador, creyendo erróneamente que se trataba de un documento de repoblación cuando es una revisión de las condiciones en las que se encuentran los pobladores de Villanueva de Pampaneto con respecto al abad o regente de este arcestorio. GONZÁLEZ 1833, p. IX, n. 220, GOVANTES 1846, p. 109, UBIETO 1981, n. 33 y JIMENO y PESCADOR 2003, n. 64.

39 De acuerdo con Martín Duque al tratar acerca de la potestad regia, en diplomas falsos se suele anteponer el territorio de Aragón al de Pamplona. MARTíN 2007, p. 159.

40 GOÑI 1979, pp. 160-187.

41 Ponce, que había sido abad del monasterio de Sant Serni de Tabernoles (Anserall, Lérida, Cataluña) se unió a la corte de Sancho Garcés III. Después fue obispo de Oviedo ( 1028-1035), aunque a partir de 1030 aparece en la corte que acompaña al monarca pamplonés y, por orden de éste, en 1032, se encargó de la restauración del obispado de Palencia, a cuyo cargo figuró hasta 1035, en que fue nombrado su primer obispo en la sede restaurada. MARTíNEZ 1984, p 164, RIU 1989, pp. 430-436, FORTÚN 2005, pp. 219-220, MARTÍN 2007, pp. 38-39 y 265, y MARTÍNEZ 2007, pp. 216 y 221-224.

42 Uno de los Fortún Sánchez es el conocido como Buen Padre, colactáneo o hermano de leche de Sancho Garcés III y ayo y preceptor de García Sánchez III, y fue señor de Nájera (1023-1054). Mientras que el otro era uno de los señores que solían acompañar al rey. MORET 1766, n. 41, pp. 53 y 505, LEZA 1959, p. 10, VICUÑA 1971, pp. 137-138, UBIETO 1973, pp. 212-213 y CANELLAS 1979, pp. 137, 139 y 155, PESCADOR 1999, pp. 121, 123, MARTÍN 2007, p. 323 y MARTÍNEZ 2007, p. 242.

43 Fortún Ochoaz, señor de Viguera (1013-1050/4) fue el cabeza del linaje Fortuñones y primer señor de los Cameros. Dos de sus hijos, Jimeno y Sancho Fortuñones, escogieron como panteón familiar el monasterio de San Prudencio de Monte Laturce y lograron incorporarlo a su patrimonio señorial, en marzo de 1058, cambiándoselo al monasterio albeldense por el de San Miguel de Biurco (Yécora, Álava), que le había sido concedido a Sancho Fortuñones por el rey pamplonés, Sancho Garcés IV, a finales de 1057. García Turza identificó esta fecha como la del final de la dependencia del monasterio de San Prudencio del albeldense, inaugurando su segunda etapa, en la que pasó a formar parte de las propiedades de los señores de Cameros, hasta 1181, año el que el monasterio comenzó su tercera etapa tras aceptar los usos y la obediencia cisterciense, liberándose de la protección señorial. Cabe añadir que Grana- 
documento original, habría que considerarlo como apócrifo y compuesto en época posterior, quizá, basándose en documentos cuyos contenidos originales fueron manipulados, y que como ya no se conservan, no se puede comprobar cuánto conserva de autenticidad. Es más, cabría la posibilidad de que esta documentación datase del reinado de su hijo y rey de Pamplona, García Sánchez III, ya que éste, junto con su esposa Estefanía, confirmó esta concesión de términos a Villanova de Pampaneto, el 1 de enero de 1044, estando en Viguera ${ }^{44}$. De ahí que el hecho de que en el documento inicial figure quam fecimus in vita nostra [de Sancho Garcés III], parece corresponder a una redacción anómala en un documento que datase de la época en que vivió el propio monarca y no así en uno redactado durante el reinado de su hijo y, quizá, presentado a éste para su confirmación. A no ser que se trate de un documento generado o recreado con posterioridad al reinado de García Sánchez III.

De modo que de los cinco documentos con los que se comenzó, el único documento del cartulario albendense, relacionado con este monasterio, que aún podría ser considerado de la época de Sancho Garcés III sería el expedido en el propio monasterio de Albelda, en $1033^{45}$, cuyo contenido se refiere a la donación del estratégico castillo riojano de Clavijo ${ }^{46}$, así como de Cuvellam ${ }^{47}$, con que le obsequió dicho monarca pamplonés.

do y Fernandez de la Pradilla recuperaron la información también citada por Esteban Oca, Ángel CaneIlas, García Turza y Fernández de la Pradilla acerca de que Mencia, hija de García Sánchez III y hermana de Sancho Garcés IV, fue quien casó con Jimeno, el hijo de Fortún Ochoaz. En lugar de considerar que dicha infanta estuvo casada con éste, como recogieron Llorente, Govantes, García Turza y Peterson y consta en los documentos de San Prudencio de Monte Laturce pero que, claramente, contienen cláusulas anómalas que hacen dudar de la autenticidad de la información que contienen. Finalmente, Peterson recuperó la posible conexión dinástica de Fortún Ochoaz con los Banu Qasi, llegando a plantear una relación entre el núcleo patrimonial de los Banu Qasi, en el siglo IX, el reino de Viguera, en el siglo X, y el territorio controlado por Fortún Ochoiz, en el siglo XI. Así como que la incorporación de este territorio al reino pamplonés pudo estar relacionada con un posible pacto entre una línea dinástica menor que pudiera haber sobrevivido de los Banu Qasi en la zona, concretamente de uno de los Lope que se convirtieron al cristianismo Ibn Mohamed, y que hubiesen decidido pactar con Sancho Garcés I. Aunque reconociendo las graves dificultades pendientes de resolver acerca de las incógnitas que plantearía esta posible continuidad. Hipótesis que partía ya contaminada por el error de Peterson de considerar a Fortún Ochoaz como esposo en vez de suegro de Mencia. LLORENTE 1807, pp. 370-371 y 396, GOVANTES 1846, pp. 45 y 172-173, OCA 1913, p. 47, CANTERA 1951a, pp. 175-176, LEZA 1959, pp. 9-12, CANTERA 1961b, p. 438, VICUÑA 1971, p. 133, UBIETO 1973, p. 212, UBIETO 1976, nn. 268 y 407, CANELLAS 1979, p. 155, UBIETO 1981, nn. 40-43, SÁINZ 1981, nn. 2 y 5-6, GARCÍA 1989, p. 144, FERNÁNDEZ DE LA PRADILLA 1991, pp. 264 y 268, GARCÍA 1992, pp. 15, 17 y 28-29, y nn. 2 y 4-6, FERNÁNDEZ DE LA PRADILLA 1994, p. 43, LÁZARO 1997, p. 379, GRANADO y FERNÁNDEZ DE LA PRADILLA 1999, p. 31 y PETERSON 2005, pp. 18 y 21-24.

${ }_{44}$ GONZÁLEZ 1833, p. IX, n. 220, GOVANTES 1846, pp. 212-213, UBIETO 1981, nn. 33 y 35, y JIMENO y PESCADOR 2003, n. 75.

45 UBIETO 1981, n. 34 y JIMENO y PESCADOR 2003, n. 75.

${ }^{46}$ El estratégico castillo de Clavijo se encuentra ubicado entre los ríos Leza e Iregua. RUíZ-NAVARRO 1972, pp. 154-156 y RUÍZ-NAVARRO 1990, pp. 54-55.

47 Mercedes Lázaro creyó que el monasterio albeldense fue el destinatario tanto del castillo de Clavijo como de la cella de Cuvellam, a la que Govantes había identificado con Cobilella, Cuevilla o Vilella, reduciendo erróneamente Cobilella y Vilella, a la vez que ubicó correctamente a esta última a la izquierda de la calzada romana caminando desde Logroño, entre Murillo y Agoncillo. Cantera Orive también identificó Vilella con Velilla de Agoncillo pero como un lugar distinto de Covilella, que ubicó entre 
Pampaneto, el monasterio de San Fructuoso y su influencia en la organización...

En este documento sólo se cita la confirmación del obispo Sancho ${ }^{48}$, lo que podría ser una rareza a la que se sumaría la del anómalo hecho de que un castillo, aunque ya estuviese en la retaguardia, fuese donado a una comunidad monástica y si a esto se suman las referencias que se hacen en el texto a «ut neque ego neque nullus filiorum meorum, nepotum aut pronepotum» y a «Quicumque igitur filiorum meorum, nepotum aut pronepotum», cabría considerar la posibilidad de que hubiese sido escrito varias generaciones después y no en vida de Sancho Garcés III.

Sin embargo, hay que tener en cuanta que sólo tres años después de la reconquista definitiva de Calahorra, el monasterio de Albelda dispuso de su CuveIlam como moneda de cambio para hacerse con Pampaneto, lo que da cierta verosimilitud al contenido de esta donación, de la que habitualmente sólo se destaca la parte relacionada con el castillo de Clavijo. Aun así, en la búsqueda de la fidelidad del propio documento, aún quedaría pendiente de explicación la extraña advocación del monasterio que figura en esta donación: Ego Sancius, gratia Dei rex, dono ecclesie in honore Dei Patris et Filii et Spiritus Sancti dedicate et sanctorum eius confesor pontificum Martini, Cipriani, Adrianit9 nominibus et merite consecrate $^{50}$.

Agoncillo y Murillo de Río Leza, basándose en lo dispuesto en el testamento de la reina Estefanía, fechado en 1060. Concretamente, en la manda que la reina dejó para su hijo Raimundo se describen: Murillo [de Río Leza], Cobiela, Villiela, Egón y Egoncillo con sus términos. Además, Cantera identificó Egon y Egoncillo con Agoncillo y Arrúbal (La Rioja), sin poder dilucidar cual era cual. Mientras que Urbano Espinosa, así como Pascual y Pascual identificaron Egón con el primitivo asentamiento de Agoncillo, ubicándolo al noroeste de esta población, a la vez que la mansio Barbariana en el término de Barbarés (Murillo de Río Leza) y Velilla en Agoncillo, en la margen izquierda del río Leza. GOVANTES 1846, pp. 4 y 124, CANTERA 1958, pp. 312 y 314, CANTERA 1962, p. 334, RODRÍGUEZ 1992, n. 18, FERNÁNDEZ DE LA PRADILLA 1994, p. 39, ESPINOSA 1994, pp. 123-124, PASCUAL y PASCUAL 1994, pp. 348-349, 352, 359-360 y 397, y LÁZARO 1997, p. 376.

48 La copia del documento que se ha conservado de esta curiosa e interesante donación de una estratégica posición militar a un monasterio carece de escatocolo y sólo consta que fue realizada bajo la supervisión del obispo Sancho, sin especificar su sede. Tratándose de un documento del rey de Nájera y Pamplona, es podría tratarse del obispo de Pamplona, Sancho (1024-1052), que previamente había sido abad del monasterio de Leire, o de su homónimo Sancho (1024-1046), obispo de Nájera y abad de San Millán desde 1028 hasta 1039, año en el que le sucedió Gomesando, quien también le sucedió después como obispo de Nájera, entre 1046 y 1065. A pesar de las discrepancias planteadas por Goñi Gaztambide y de los errores introducidos por Sáinz Ripa, resueltos en parte por Canellas y del todo por Fortín Pérez de Ciriza al tratar acerca de la configuración del sistema de los obispos-abades bajo Sancho Garcés III. Sin embargo, dado que el documento especifica que el rey lo firmó et sub cura et providentia et prenominatu venerabilis episcopi Sancii ordinandum et regendum omnis que ad prefatam domun Domini pertinente, concessi, debería tratarse del obispo de Nájera. GOÑI 1979, pp. 160-187, CANELLAS 1979, pp. 147-148, UBIETO 1981, n. 34, SÁINZ 1994, pp. 213-246 y FORTÚN 2005, pp. 213-217 y 223.

49 Margarita Cantera sólo registró el culto al mártir de Nicomedia (Izmit, Turquía), San Adrián, en Torrijas, donde también localizó la existencia de culto a San Ciprián en un monasteriolo de titularidad privada, pues su propietaria se entregó con él, en 1092, al monasterio albeldense. Aunque Cantera hizo referencia a Torrijas, se trata de la villa de Torrillas que, según M. ${ }^{a}$ Pilar Pascual, Hilario Pascual y Pedro García se encontraba entre las localidades riojanas de Lardero y Logroño. UBIETO 1981, nn. 64, 68 y 78, CANTERA 1985, p. 53, FERNÁNDEZ DE LA PRADILLA 1991, p. 268 y PASCUAL, PASCUAL y GARCÍA 2005, pp. 154 y $159-160$.

50 Tomás González destacó que, en estos momentos, la advocación del monasterio albeldense era la de San Martín, San Cipriano y San Adrián. GONZÁLEZ 1833, p. IX, n. 221. 
En caso de superarse estas pegas, se podría concluir con que sólo este documento de Sancho Garcés III, de entre los cinco que figuran en el cartulario albeldense y que supuestamente estaban relacionados con este monasterio riojano, sería coetáneo o, mejor dicho, aparentaría mayor credibilidad de no haber sufrido modificaciones o de no tratarse de una flagrante falsificación. Caso éste que conduciría a la conclusión de que todos los documentos albeldenses fechados durante el reinado de este monarca pamplonés serían apócrifos.

\section{LA INCORPORACIÓN DE PAMPANETO AL MONASTERIO DE ALBELDA}

Además de la mencionada confirmación otorgada por García Sánchez III y su esposa Estefanía de la concesión de términos y condiciones de población que, supuestamente, había concedido Sancho Garcés III a Villanova de Pampaneto, se conservan otros tres documentos concedidos por estos monarcas pamploneses que hacen referencia a Pampaneto. Dos de estos documentos están fechados en noviembre de 1048 y se corresponden con las redacciones complementarias del intercambio que, supuestamente, realizaron los citados monarcas con el obispo Gomesando y los otros hermanos que convivían con él, en el monasterio de Albelda ${ }^{51}$; mientras que el tercero, aparentemente, no guarda relación con Pampanito, aunque sí con el monasterio albeldense.

De acuerdo con el primero de estos tres documentos, escrito y firmado en Albelda, García Sánchez III y su esposa Estefanía dieron al monasterio albeldense el monasterio al que llamaban Pampaneto, junto con su villa de Villanova, incluyendo sus tierras, viñas, huertas y un molino, así como un huerto en villa Auria ${ }^{52}$, concretando que Villanova estaba situada junto a Zenzano ${ }^{53}$; y, a cambio, los monarcas pamploneses recibieron una celda o monasterio que se llamaba Quevellam o Covela, con todas las pertenencias y términos que le rodeaban ${ }^{54}$.

51 Gomesando fue consagrado como obispo de Nájera en 1046 y desde el año siguiente, dejó de ser abad de San Millán y también pasó a gobernar su obispado desde el monasterio albeldense, del que fue su abad entre 1048 y el final de su vida, como precisó Fortín Pérez de Ciriza corrigiendo a Sáinz Ripa, aunque éste creyó que sólo constaba que residió en él en 1059, sin tener en cuenta el texto de este documento. SÁINZ 1994, pp. 225-235 y FORTÚN 2005, pp. 223-225.

52 Las citadas posesiones de Pampaneto parecen estar ubicadas a su alrededor, con la excepción del huerto que estaba en la ilocalizada villa Auria. Topónimo que se conserva en la localidad riojana de Hormilleja, situada al norte de Nájera y al suroeste de donde se ubica la mansio Atiliana (Ventas de Valpierre, Briones). GONZÁLEZ 1987, p. 599, CANTERA 1964b, pp. 376-385, y ALONSO y JIMÉNEZ 2008, p. 194.

53 Govantes y Mercedes Lázaro señalaron la ubicación de Villanova de Pampaneto junto a Zenzano, citando este documento. GOVANTES 1846, p. 212 y LÁZARO 1997, pp. 375-376.

54 Canellas confundió el inexistente monasterio de Villafranca con Villanova de Pampaneto y no concretó detalles acerca de la existencia de los dos documentos complementarios. El primero de ellos fue redactado por orden de los monarcas pamploneses y está fechado en noviembre de 1048, mientras que el segundo concreta que fue el día 1 de dicho mes y se corresponde a la redacción ordenada por el obispo Gomesano y los monjes del monasterio de Albelda. CANELLAS 1979, p. 149 y UBIETO 1981, nn. 36-37. 
Pampaneto, el monasterio de San Fructuoso y su influencia en la organización...

En este documento constan, además de las confirmaciones de los mencionados reyes de Pamplona y del citado obispo de Nájera, las del obispo de Pamplona Sancho, y la de García II (1037-1055), obispo de Álava ${ }^{55}$, así como las de los señores Fortún Sánchez, de Nájera, Fortún Ochoaz, de Viguera, Aznar Fortuñones, de Huart ${ }^{56}$, Sancho Fortuñones, de Pancorbo (Burgos), Fortún López de Ulli, de Clavijo ${ }^{57}$, otro Sancho Fortuñones, de Calahorra ${ }^{58}$, Jimeno Fortuñones, en Arnedo ${ }^{59}$, un tercer Sancho Fortuñones, de Funes (Navarra), García Sánchez, de Vesga ${ }^{60}$, Aznar Sánchez, de Monasterio de Rodilla (Briviesca, Burgos) y Peralada de Bureba (Aldea de Portillo de Busto, Burgos), Sancho López, de Poza de la Sal (Burgos), Jimeno Sánchez, de Arlanzón (Burgos), García Aznárez, de Auca (Villafranca de Montes de Oca, Burgos) y el conde de Álava, Munio Muñoz. Esto es, la mayoría de los principales señores de la frontera suroccidental del reino de Pamplona en este momento.

Además, cabe destacar que a García Sánchez III se le cita como rey en Pamplona, en Álava y en Castilla La Vieja, junto a su hermano Fernando I el Magno (1037-1065), que figura como rey en León y en Burgos, y al hermano de ambos Ramiro I (1035-1069), que consta como quasi pro rege en Aragón, en Ribagorza y en Sobrarbe, siendo esta última una posible inconsistencia que se constata en el documento, ya que Ramiro nunca se atrevió a firmar como rey ${ }^{61} \mathrm{y}$, aunque aquí tampoco figure como tal ${ }^{62}$, es posible que el documento sea apócrifo, ya que en él se duplica la descripción de los objetos del intercambio y no se hace de forma consistente. La primera vez se dice que los reyes pamploneses les conceden a los albeldenses monasterium quod dicitur Pampanetum, cum sua villa que dicunt Villanova, qui ist sita iuxta Senzano, adque cum suis terris et vineis adque hereditatibus, vel cum suis ortibus seu et molendinibus, sive et unum ortum in Villa auria, lo que

\footnotetext{
55 García era monje de San Millán de la Cogolla cuando fue consagrado como obispo, en 1037 y es posible que residiese en dicho monasterio, al menos, esporádicamente. MAÑARICUA 1964, pp. 82-101 y FORTÚN 2005, p. 226.

56 Ugarte (Baracaldo, Vizcaya). LACARRA 1972, p. 236, OLABUENAGA 2001, pp. 2 y 8.

57 Ubieto registró esta cita de Fortún López en Clavijo, en 1048. UBIETO 1973, p. 211.

${ }_{58}$ Este Sancho Fortuñones, que estuvo a cargo de Calahorra entre los meses de noviembre de 1048 y 1050, es el citado hijo de Fortún Ochoaz. UBIETO 1973, p. 274.

59 Jimeno Fortuñones, que estuvo a cargo de Arnedo en las mismas fechas que su hermano Sancho lo estuvo en Calahorra. UBIETO 1973, p. 236.

${ }^{60}$ El lugar no identificado de Verilea se trata de una mala transcripción de Vesga o Las Vesgas (Los Barrios de Bureba, Burgos), donde Canellas recogió a García Sánchez como tenente de Tariego (10401050). Mientras que Aitor Pescador ubicó a García Sánchez en Tabieco (1040-1044). CANELLAS 1979, p. 155, MARTÍNEZ 1987, pp. 96-98, RODRÍGUEZ 1992, n. 3, PESCADOR 1999, p. 135 y GURRUCHAGA 2003, p. 220.

61 Aunque con tradición condal, si quiera remota, y base geográfica propias, Aragón había dejado de considerarse un condado, comitatus, desde que a mediados del siglo $X$ fue gobernado en honor, por un "hijo de rey", proles regis, que, por tanto, se hubiese considerado degradado con el título de conde, comes. El supuesto se planteaba también en Castilla y Ribagorza: en este último condado se había desechado la referencia condal en cuanto lo rigió Sancho el Mayor. LADERO, MATTOSO, MARTÍN, UDINA, FORTÚN y SESMA 1998, pp. 265-266.

62 La cualificación de quasi pro rege que se le atribuye a Ramiro I fue aceptada por Martín Duque ya que con ella justificó la disposición de Aragón que hacía en bajulia, tutela o protección de García Sánchez III. MARTíN 2007, p. 348
} 
puede ser el resultado de una interpolación con objeto de detallar las propiedades que acompañaban a Pampaneto. Mientras que la segunda vez sólo se hace ver que García Sánchez III y Estefanía aceptaron de ellos unam cellulam que vocitatur Quevellam, cum Omnia sua pertinentia, ut possideamus eam nos et filiis et filiabas nostris per in secula futura. Por lo que hay que concluir que se trata de un documento apócrifo e interpolado con posterioridad, o incluso de una falsa recreación que, en cualquier caso, no está basada en una copia fidedigna del original si es que alguna vez lo hubo.

Por otra parte, el segundo documento es de propósito similar al anterior, precisando que data del 1 de noviembre de dicho año 1048, y corresponde a la redacción supuestamente ordenada por el obispo y los monjes de Albelda, contando con el consentimiento de los citados obispos de Pamplona y Álava, en la que se detalla el coto redondo de Covela: a parte Apersaltis que nominatur Matha Aranionis ${ }^{63}$, per utrorumque marginum flumina Cliventia?, usque scilicet gestans crucem de lurrectius ad villaulam que vocatur ecclesiam Sancti Martin ${ }^{64}$, inde etenim per semitam que graditur ad villam Antiquitatis ${ }^{65}$, hinc vero contra meridiem que

63 En Alcanadre (La Rioja) se conserva el topónimo de La Mata, en el que, además, existe la ermita de Aradón. Según Daniel Alonso, único vestigio de la población homónima que acabó formando parte de Alcanadre. Lo que permite plantear la identificación de ésta con Matha Aranionis. GONZÁLEZ 1987, p. 58 y ALONSO 1957, p. 200.

64 Se trata de San Martín de Berberana (La Rioja) que debe su nombre a un monasterio que, como recogió Cantera Orive, está documentada su existencia en 947, siendo errónea la cita de Cantera Montenegro, a quien siguió Fernández de la Pradilla, relativa al año 946, ya que en este caso, no se menciona al monasterio sino a las villas de Barberana y Barberanilla que fueron donadas al monasterio de San Millán de la Cogolla. De acuerdo con Pascual y Pascual, estuvo junto a una calzada secundaria. Lo que ayudaría a entender la existencia de las referencias a la calzada antigua y mayor, siendo esta última la principal vía romana del Ebro que comunicaba Graccurris (Alfaro, La Rioja) con Vareia (Varea, La Rioja), Ab Asturica Tarracone. CANTERA 1964a, p. 138, UBIETO 1976, nn. 41, 45, 87 y 346, CANTERA 1985, p. 55, FERNÁNDEZ DE LA PRADILLA 1991, p. 263 y PASCUAL y PASCUAL 1994, p. 397.

65 Sáenz Preciado, seguramente inspirado por la errónea reducción de Govantes, identificó esta villa antigua con el yacimiento arqueológico del término el Juncal de Velilla (Agoncillo) y también erró al creer que este documento albeldense trataba de una permuta de posesiones entre Gumesando, obispo de Calahorra y el Monasterio de Albelda. Sin embargo, Sáenz Preciado acertó al identificar el citado yacimiento de Agoncillo, después conocido como Velilla de Aracanta, con el lugar de Villiela citado en el testamento de la reina Estefanía, y haciendo, además, referencia a un documento de 1257 acerca de Villiela

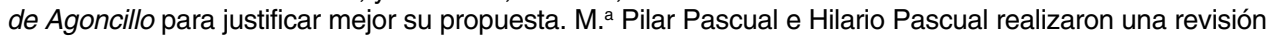
exhaustiva y crítica acerca de la ubicación de la mansio Barberiana en la historiografía moderna y también de la documentación medieval. En esta última, recogieron la referencia a este documento albeldense y coincidieron con lo erróneamente expuesto por Sáenz Preciado acerca de la identificación de la villa antigua con Villiela y del propósito del documento. Finalmente, Asunción Antoñanzas cuestionó la propuesta de Sáenz Preciado acerca de la existencia de una basílica paleocristiana en Velilla de Aracanta recogida en la historiografía moderna, confirmando la existencia de una villa romana que perduró hasta la Baja Edad Media, constando que ya estaba despoblada en 1506. Por otra parte, es posible que esta villa antigua no sea otra que los restos de la mansio Barberiana, permitiendo así realizar su actual localización, no lejos de donde ya la ubicaron Govantes y Urbano Espinosa, a la vez que siguiendo la propuesta de éste acerca del trazado principal de la calzada romana, ésta servía de límite meridional hasta el cerro de la Atalayuela (Agoncillo), desde donde se.dirigiría hacia el río Leza en dirección suroeste, hacia Murillo de Río Leza, y sin cruzar el puente romano, ubicado donde propuso Espinosa, seguiría el curso del río hacia su desembocadura. Aunque este último tramo no lo hacía íntegramente por el curso del propio río sino por el de la acequia que salía de él y llevaba a la presa de Muño Zulli. Lo que además confirmaría la propuesta de Carmen Alonso y Javier Jiménez que descartaba el cruce del río Leza por el puente me- 
pergitur usque ad antiquam calzatam, a calzata vero que itur contra Baieram ${ }^{66}$ donec pervenitur ad Apersaltum, ab ipso loco igitur calzata maiore contra Murellum per rivolum Leze $^{67}$ ab utriusque insulis ${ }^{68}$, cum limpha rigatice die noctisque, usque ad presam Munionis Zullip9. Siendo ésta, Covela ${ }^{70}$, la propiedad recibida entonces por el monasterio albeldense, junto con el castillo de Clavijo.

Es curioso que en este documento que encargó realizar el obispo Gomesando y en el que figura confirmándolo junto con los citados obispos de Pamplona y Álava, así como con los señores Fortún Sánchez, de Nájera, Fortún Ochoaz, de Viguera, Sancho Fortuñones, de Pancorbo, Aznar Fortuñones, de Ugarte, Iñigo López, de Clavijo, Sancho Fortuñones, de Calahorra, Jimeno Garcés, de Azagra (Navarra) $^{71}$, Sancho Fortuñones, de Funes, y otro Sancho Fortuñones, de Tafalla, no figura la confirmación de García Sánchez III.

dieval que consideraron como romano M. ${ }^{\text {a }}$ Pilar Pascual e Hilario Pascual, siguiendo a varios autores, y permitiría confirmar la propuesta inicial acerca de la ubicación del puente romano sobre el río Leza, aguas arriba del medieval y donde lo había ubicado Urbano Espinosa. GOVANTES 1846, pp. 4 y 124, RODRÍGUEZ 1992, n. 18, SÁENZ 1994, pp. 77-78, ESPINOSA 1994, p. 140, PASCUAL y PASCUAL 1994, pp. 327-332 y 348, ANTOÑANZAS 2003, p. 111-114 y 136-139, y ALONSO y JIMÉNEZ 2008, pp. 194 y 205207.

66 Varea.

67 En el museo arqueológico de Logroño, según José Manuel Ramírez, se conserva un ara dedicada a Mercurio, cuyo culto se haya ligado a una calzada por ser el protector de los viajeros, que fue hallada en el término de Murillo de Río Leza, donde pudo haber un campamento romano que protegiera la calzada que corría paralela al curso del río Leza y que, como señalaron $\mathrm{M}^{\mathrm{a}}$ Pilar Pascual e Hilario Pascual, se dirigía hacia la meseta, cruzándose en este lugar con la citada vía principal vía del Ebro. RAMíREZ 1973, p. 5 y PASCUAL y PASCUAL 1994, p. 336.

68 Las dos islas se corresponden con el término de Las Tamarices, que son las islas que se forman en la desembocadura del río Leza en el Ebro, al N. O. de Agoncillo, de modo que este tramo del coto se correspondería con el tramo del cauce del río Leza hasta su desembocadura, desde el citado cruce de calzadas de Murillo del río Leza. Aunque M. ${ }^{a}$ Pilar Pascual e Hilario Pascual no los relacionaron con este documento, sí lo hicieron, citando a Cantera Orive, al comentar el amojonamiento de Sagoncillo (Agoncillo) otorgado por Sancho Garcés IV. CANTERA 1944, p. 64 y PASCUAL y PASCUAL 1994, p. 332.

${ }_{69}$ Al igual que ocurría ante la desembocadura del río Alhama en el Ebro que estudiaron José Antonio Hernández, Enrique Ariño, José Manuel Martínez y Julio Núñez, por ejemplo, también debió existir una presa ante la desembocadura del Leza. Además, es posible que los sillares sueltos y otros restos encontrados cerca de la desembocadura del río Leza en el Ebro y citados por M. ${ }^{a}$ Pilar Pascual e Hilario Pascual como pertenecientes al supuesto puente romano, pudieran pertenecer a los restos de esta presa. PASCUAL y PASCUAL 1994, p. 348 y HERNÁNDEZ, ARIÑO, MARTíNEZ y NÚÑEZ 1999, pp. 240-245.

70 Omitiendo los detalles correspondientes a todo el salto o pequeño acantilado que discurre a lo largo de la orilla derecha del Ebro, entre la desembocadura del río Leza y Mata Aranion (ermita de Aradón, Alcanadre), por ambas orillas del riachuelo o meandro Cliventia, siguiendo todo el camino atravesando el cruce que lleva a la pequeña villa que llaman Iglesia de San Martín, desde allí por la senda que sube hasta la villa antigua, desde aquí continúa hacia el sur hasta la calzada antigua, por esta calzada en dirección a Varea hasta llegar a la citada zona acantilada y omitida que va desde la desembocadura del Leza y su continuidad por la orilla del Ebro hasta la ermita de Aradón, esto es, desde dicho lugar de la villa antigua por la calzada mayor hacia Murillo y siguiendo por el curso del río Leza, aunque desde las dos islas por la acequia con la que se riega de día y de noche, hasta llegar a la presa de Muño Zullo y después a la citada desembocadura. Cabe señalar que una parte de este amplio coto redondo de Covela, concretamente su mitad occidental, parece coincidir con la descripción recogida por Cadiñanos Bardeci acerca del coto redondo del término que, en 1489, Lope de Porras arrendó a los vecinos de Agoncillo y que iba de una parte del río Leza que parte término con Aracanta a Velilla fasta el moxon de la villa de Murillo e fasta el término de Arrubal. CADIÑANOS 1982, p. 117.

71 Ubieto registró en Tafalla a Jimeno Garcés (1046-1062). UBIETO 1973, p. 238. 
También cabe recalcar que presenta una anómala cláusula acerca de la potestad de éste y de sus hermanos: reinante Domino nostro Ihesu Christo et sub Rius presidio Garsea prefatus rex in Pampilona, in Alava et in Castella vetura, et Rius frater Fredinandus rex in Legione et in Burgus et illorum frater Ranimirus rex in Aragone et in Ripagurcia et Suprarbi. Por lo que también hay que concluir que se trata de un documento falso o, cuando menos, interpolado o recreado con posterioridad y seguramente con objeto de incluir el detallado coto redondo de Covela ${ }^{72}$.

Es posible que la redacción de este documento del cartulario del monasterio de San Martín de Tours de Albelda sea consecuencia de posibles disputas acerca de los límites territoriales que acaecieron con posterioridad y que requirieron la citada manipulación documental, como también lo pudo ser el caso de la delimitación de otro término que, sorprendentemente, parece estar incluido completamente en la demarcación del coto anterior y que se describe en un documento de 1042, procedente del cartulario del monasterio de San Millán de la Cogolla, por el que García Sánchez III deslindó los límites de la actual villa de Arrúbal (La Rioja), citada como Halubarri ${ }^{73}$, con el monasterio de San Martín de Berberana (La Rioja) ${ }^{74}$. En él se dice que Ad hanc questionem veni illuc, cum meis subditis, Sicut michi visum fuit determinavi, id est de illo Sotello cluso de sursum parte; per linea directa ad illos iulacares ${ }^{75}$ adsummante a mata de Arangone ${ }^{76}$; in media linea predicta posui pedem meum et molionem in teste. Deinde per illa calçata qui pergit a Calaburra ${ }^{77}$. De illa vero calçata, per summum lumbum magnum de Pinna alba, usque Iberi. Deinde ad

72 Fortín Pérez de Ciriza creyó que el segundo documento era una versión falsificada del primero, en la que el otorgante pasó a ser el obispo Gomesando, señalando que el objetivo de la interpolación fue la inclusión de la delimitación de la célula de Cuevilla a la que, erróneamente calificó como cilla. Además, señaló que el objetivo de la falsificación quedaba patente en la última línea del documento, añadida tras el escatocolo: Hec scripto finis plenam retineat firmitatem. FORTÚN 2005, p. 245.

${ }^{73}$ Govantes se topó con la identificación de Arrúbal como Alubar en un documento de 1200, recogido por Llorente, acerca de la asignación de rentas a la mesa capitular de Calahorra; aunque no estaba seguro de que no se tratase de una errata existente en dicho documento. Cantera Orive registró que una de las formas en las que se hace referencia a Arrúbal en los documentos antiguos de un cartulario de Santa María La Real de Nájera, del año 1209, era Castillo Rubio y, después, Alubar. Ubieto erró al no considerar esta reducción toponímica y mantener Halubarri o Alubarri ilocalizada. Dato que si tuvo en cuenta Fortín Pérez de Ciriza, aunque no lo aclaró y lo dio por supuesto. LLORENTE 1807, n. 193, GOVANTES 1846, p. 19, CANTERA 1958, pp. 308 y 314, UBIETO 1976, n. 218 y FORTÚN 2005, p. 238.

${ }_{74}$ C. III. De confirmatione terminum de Sancti Martini de Barberana. Sub nomine Christi. Hec est pagina confirmatinis Quam fieri iussi ego rex Garseani Sancii in honore scilicet Sancti Martini episcopi. Temporibus transactis habuerunt contemptionem monachis de Sancti Martini cum hominis de Halubarri et vecinis villarum pro termino. M. ${ }^{a}$ Pilar Pascual e Hilario Pascual también citaron este documento como complementario al albeldense que describe Covellam, aunque no cayeron en la cuenta de la relación existente entre ambos. Además, citando la escritura publicada por Govantes relativa a la donación de Villanova de Sagoncillo (Agoncillo) al monasterio de San Juan de la Peña (Huesca) que hicieron Sancho Fortuñones y su esposa Blasquita, inmediatamente después de comprársela a Sancho Garcés IV, el 29 de enero de 1056, creyeron reforzar la identificación de Villiela con la citada villa antigua como oposición a esta Villanova. GOVANTES 1846, p. 4, UBIETO 1976, n. 218 y PASCUAL y PASCUAL 1994, p. 332.

75 Dutton recogió la referencia en este documento al campo con aulagas o aliagas y expuso su valor como leña, en construcción de techos y defensas así como pienso de invierno, después de ser molida. DUTTON 1980, pp. 17-18.

76 Matha Aranione.

77 Calahorra. 
Sotum de Sancti Martini ${ }^{78}$; illum vero Sotum non divisum, set totum cum illis, Cannales usque Sotello cluso. Hec predictum terminum, pro remedio anime mee et parentum meorum, sanum et integrum confirmo ad predicti almi confessoris per in seculum seculi ${ }^{79}$. Constando que este documento fue oído y confirmado por los obispos Sancho y García ${ }^{80}$, así como por los señores Fortún Sánchez, nutricio del rey, Sancho Fortuñones y Aznar Garceiz, siendo testigos Álvaro Fortuñones ${ }^{81}$ y Aznar Blascoz.

Cabe señalar que la delimitación de este segundo coto redondo, que incluía los términos inmediatamente próximos a la margen derecha del Ebro que hay entre la ermita de Aradón ${ }^{82}$, ubicada en el término de la Mata (Alcanadre) ${ }^{83}$, en el actual límite entre esta última y San Martín de Berberana, en dicha orilla del río, podría explicarse si los vecinos de Arrúbal hubieran pretendido extender sus dominios apropiándose de toda la orilla fluvial que le debía corresponder a San Martín de Berberana. Conflicto que bien pudo ocurrir seis años antes de que Covellam pasase a formar parte de las pertenencias del monasterio albeldense y, de ahí, que

78 San Martín de Berberana.

79 Desde el sotillo cerrado de la parte superior, en línea recta hasta los ulagares por los que se asoma a Mata de Arañón, en mitad de la citada línea puse mi pie y el mojón en tiesto. Desde allí por la calzada que lleva a Calahorra. Por dicha calzada, por encima de la gran loma de Peña Alba, hasta el Ebro. Desde allí hasta el soto de San Martín, incluyendo a todo él con los cañaverales hasta el sotillo cerrado.

80 Puede tratarse del citado obispo de Pamplona, Sancho (1024-1052) o de Nájera, Sancho (10241046), y de García II (1037-1055), obispo de Álava. Lo que permitiría fijar el documento entre 1037 y 1046 o 1052, por lo que esto no es un indicio de su anacronismo.

81 Podría tratarse de un error del copista, confundiendo a Aznar Fortuñones, hijo de Fortún Ochoaz, con un desconocido Álvaro Fortuñones; tratarse de una persona no emparentada con los primeros señores de los Cameros o un indicio de que el documento fue manipulado con posterioridad.

82 La ermita de Aradón se encuentra a unos $6 \mathrm{kms}$. al noroeste de Alcanadre, siendo su virgen la patrona de esta localidad riojana. Como recogió Alonso, el valle conocido como Salto Royo - actual Soto de Gorría- y ubicado bajo Aradón fue donado por Sancho Garcés IV al monasterio de Irache (Ayegui, Estella, Navarra), en 1067, así como reprodujo el documento por el que Alfonso VII donó Alcanadre al magnate de origen pamplonés Rodrigo de Azagra, en 1147, como recompensa que por el apoyo que éste le había dado en la toma de la ciudad de Baeza (Jaén, Andalucía), así como, citando a Llorente, también reprodujo el documento datado en Agreda, de 1152, por la que el citado emperador, junto con su hijo Sancho III el Deseado (1157-1158), expresaba su interés en que se edificara un monasterio benedictino femenino al que dotó con las villas de Alcanadre y Aradón. Alonso no tuvo en cuenta que la villa de Alcanadre ya había sido donada a Rodrigo de Azagra y que en dicha donación no se citaba la de Aradón, por lo que este documento no deja de ser bastante sospechoso ya que como el propio Alonso, citando otra vez a Llorente, también reprodujo el documento de julio de 1155, por el que la villa de Alcanadre fue donada por Rodrigo de Azagra, con permiso de su esposa Toda y estando en Arenzana (La Rioja), a los templarios. Lo que concuerda con el documento de 1147 y pone en serias dificultades a la supuesta donación de 1152. Especialmente porque Alonso, citando a Llorente y a Govantes, recogió la noticia de la confirmación de la donación hecha por Rodrigo de Azagra a los templarios por el rey Sancho III y su esposa Blanca, en septiembre de 1155, en Calahorra, sin que en ella se cite a Aradón. Además, entre otros documentos, Alonso también reprodujo uno datado en Estella, de 1156, por el que Rodrigo de Azagra, con permiso de su esposa Toda, donó la villa de Aradón, que había recibido del emperador, a los templarios, excluyendo el citado soto que ya había sido escindido y donado al citado monasterio de Irache. LLORENTE 1808, pp. 118-119, 154-155 y 158-159, GOVANTES 1846, pp. 8-9, LACARRA 1965, n. 41, ALONSO 1957, pp. 202-208 y ALONSO 1994, pp. 14, 18, 100-136 y 414-416.

83 El topónimo local en el que se encuentra esta ermita se conoce como Mata, en la cartografía oficial a escala 1:50.000 del Gobierno de La Rioja, aunque Daniel Alonso también reprodujo este mapa en el que figura este topónimo, lo denominó como la Mesa. Lo que sin duda le despistó. ALONSO 1994, pp. 14,18 y 20 . 
estos términos descritos en 1042 se correspondan con una parte del otro coto redondo descrito en 1048. En el supuesto de que alguno de estos dos documentos contenga información fidedigna y no demasiado manipulada con posterioridad, por supuesto.

Finalmente, dada su posible relación con el coto asociado a Covellam, también conviene recordar que existe otro documento, fechado el 29 de enero de 1056 y procedente del monasterio de San Juan de la Peña, por el que Sancho Garcés IV ${ }^{84}$ vendió Villanova de Sagoncillo ${ }^{85}$, a cambio de un caballo, un freno y una silla de plata, a Sancho Fortuñones ${ }^{86}$ y a su esposa Blasquita ${ }^{87}$, en el que se describen los términos de esta villa: Et posui termino ad Sagonziello ${ }^{88}$ in oriente usque ad illo Pueio denante Castellu rubio ${ }^{89}$, et in occidente usque ad illu vado de illo rivo unde transit via publica $^{90}$, et in septentriones ad parte de Zabuta ${ }^{91}$ usque ad illa Petra leporera ${ }^{92}$ que stat in media via, et in meridie ad parte de Ibro usque ad Ripa rubia ${ }^{93}$. Toto isto montes et valles sive aquis ad rigandum de vobis simul cum illa pieza de Sancti Estefani" ${ }^{94}$ et tamdiu vos necesse abueritis illa aqua de illo rivo per rigare, alius homo non habeat potestatem super illam, et cum omni integritate possidere hoc quod superius est scriptum, vos et filii vestir et posteritas vestra, iure quieto, usque in perpetuum ${ }^{95}$.

84 UBIETO 1963, n. 126.

${ }_{85}$ Ubieto y Cadiñanos Bardeci interpretaron que el objeto de la transacción Villanueva y Sagoncillo, mientras que, según Llorente y quienes siguieron a éste, se trató de Villanueva de Sagoncillo. Esto último coincide con la descripción de sus términos que se incluye en el documento y en el que su límite oriental es precisamente Agoncillo. LLORENTE 1807, pp. 392-395, GOVANTES 1846, p. 4, UBIETO 1963, n. 126, CADIÑANOS 1982, p. 113, CADIÑANOS 1990, p. 63 y PASCUAL y PASCUAL 1994, p. 333.

${ }_{86}$ Ubieto no incluyó la donación de Sancho Fortuñones y Blasquita al monasterio pinatense y sólo incluyó la compra que éstos hicieron al rey de Pamplona en el cartulario de San Juan de la Peña, confundiendo Villanueva de Sagoncillo con Villanueva y Sagoncillo. Mientras que Llorente había publicado correctamente este documento y la inmediata donación que de esta villa y de otras propiedades hicieron Sancho Fortuñones y Blasquita al monasterio de San Juan de la Peña. LLORENTE 1807, pp. $392-395$ y UBIETO 1963, n. 126.

87 M. a Pilar Pascual e Hilario Pascual, citando a Llorente y a Govantes, confundieron a Blasquita, hija de Galga de Guipúzcoa y de García Aznárez, con su madre. LLORENTE 1807, pp. 392-395. GOVANTES 1846, p. 4, UBIETO 1963, p. 274, PASCUAL y PASCUAL 1994, pp. 332-333.

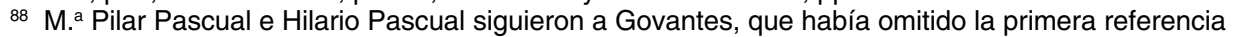
ad Sagonziello en su transcripción, y, por tanto, en la traducción que también hicieron de ella. GOVANTES 1846, p. 4 y PASCUAL y PASCUAL 1994, p. 333.

89 Llorente identificó Castillo Rubio con Arrúbal e igual hizo Cantera Orive. Sin embargo, Cadiñanos Bardeci ubicó correctamente este castillo Rubio entre Agoncillo y Arrúbal, suponiéndole un origen árabe y aclarando que había noticias suyas en el siglo XIV pero que ya no quedaban vestigios de él. LLORENTE 1807, p. 394, CADIÑANOS 1982, p. 119 y CANTERA 1958, p. 308.

90 Se trata del río Leza.

91 Zabuta, según la transcripción de Llorente y, por tanto, de Govantes así como de M. ${ }^{\text {a Pilar Pascual }}$ e Hilario Pascual, es Zabatu. Podría tratarse de un despoblado ubicado en la margen izquierda del Ebro.

92 Peña de libres o conejos, quizá porque en ella había una gran madriguera de conejos.

93 Llorente señaló que Ribarrubia es la cordillera de cerros que sigue al poniente de Agoncillo y de Arrubal hasta las Tamarices. LLORENTE 1807, p. 394.

94 Llorente identificó San Esteban con Murillo de Río Leza. Sin embargo, Margarita Cantera sólo recogió la existencia de una ermita dedicada al protomartir San Esteban en Torrijas que, en 1435 fue anexionada a la colegia de Albelda-La Redonda (Logroño), aunque dicha anexión fue impugnada tres años más tarde, y una iglesia en Galbarruli (La Rioja). LLORENTE 1807, p. 394 y CANTERA 1985, p. 52.

${ }_{95}$ El límite oriental de Villanueva de Agoncillo llegaba hasta Agoncillo, concretamente, hasta el monte que hay justo antes de Castillo Rubio, el límite occidental llegaba hasta el vado del río [Leza] por 
Nuevamente, el término acotado parece coincidir con buena parte del coto redondo asociado anteriormente a Covela, cuando ésta fue intercambiada por Pampaneto. Aunque en este caso parece que, además, incluye algunos términos en la margen izquierda del Ebro y que no entra en conflicto con el del deslinde entre Arrúbal y San Martín de Berberana. No obstante, tampoco este documento resulta ser muy fidedigno, ya que en él también se cita la errónea cláusula acerca de la condición de Ramiro como supuesto rey de Aragón: reinante Domino nostro Ihesu Christo et sub Rius imperio Sancius rex in Pampilonia, Fredinandus rex in Legione, Ranimirus rex in Aragone, Gomesanus episcopus in Sancti Emiliani, Iohannes episcopus in Irunia ${ }^{96}$, Bigilanus episcopus in Alava ${ }^{97}$. Por lo que, a falta de más información y dada la manifiesta manipulación que sufrieron estos documentos con objeto de defender diversas propiedades y derechos a posteriori, poco más se puede decir acerca de ellos o de sus respectivos contenidos.

A pesar de todo esto, parece bastante creíble que, en noviembre de 1048, el monasterio de San Fructuoso, también conocido como Pampaneto, dejara de ser un monasterio de patronato real y pasase a depender del monasterio de San Martín de de Tours de Albelda que, de este modo, también asumió la responsabilidad de la organización territorial de buena parte del valle del río Leza.

\section{LA CESIÓN DE PAMPANETO AL MONASTERIO DE SAN PRUDENCIO}

En agosto de 1065, estando en Nájera, Jimeno Fortuñones convenció al rey Sancho Garcés IV para que donase los monasterios de San Agustín, ubicado cerca de Nalda (La Rioja), y de San Saturnino de Pavía, junto con su ilocalizada villa de Pavía y todas las pertenencias de ambos monasterios ${ }^{98}$, al de San Prudencio de Monte Laturce ${ }^{99}$.

Poco después se produjo un importante cambio en la política monástica ejercida por el monarca pamplonés ya que, en abril de 1067, mandó a Munio (10651080), obispo de Nájera y Albelda ${ }^{100}$, y a todos sus monjes de San Martín de

encima del cual pasa la vía pública, el límite septentrional hasta Zabuta, concretamente, hasta la peña de la conejera que está en mitad del camino, y que el límite meridional, a esta parte del Ebro, hasta la OriIla Rubia.

96 Juan (1054-1068) fue obispo de Pamplona. GOÑI 1979, pp. 188-209.

97 Vigila o Vela (1055-1062) fue obispo de Álava, tras figurar a cargo de esta parroquia desde 1054. MAÑARICUA 1964, pp. 104-110 y FORTÚN 2005, p. 226.

98 García Turza propuso la posible cercanía de ambos monasterios a Viguera. Sin embargo, Margarita Cantera registró la existencia de noticias del monasterio de San Saturnino de Pavia, ubicado en las cercanías de Alberite, en la segunda mitad del siglo XIII. También citó la existencia del monasterio dedicado a San Agustín de Hipona, aunque no sabía si había pasado a pertenecer al de San Prudencio de Monte Laturce en el siglo XI o XII. GARCÍA 1989, p. 145, GARCÍA 1992, p. 18 y CANTERA 1985, pp. 54 y 57 .

99 Govantes dudó entre la lectura de Pavia y Papia. GOVANTES 1846, P. 173 y GARCÍA 1992, n. 9.

100 El obispo de Álava, Munio III (1062-1065), según fortín Pérez de Ciriza, pasó a ser obispo de Calahorra, donde reemplazó a Gomesando. MAÑARICUA 1964, pp. 110-118, SÁINZ 1994, pp. $247-264$ y FORTÚN 2005, pp. 225 y 227. 
Tours que cediesen a Jimeno Fortuñones y a Martín, abad de San Prudencio de Monte Laturce, el monasterio de Pampaneto y su villa de Villanova, con su iglesia y la de San Pelayo de Leza ${ }^{101}$, con sus tierras, y la de San Andrés, que estaba junto a San Fructuoso (Pampaneto) ${ }^{102}$, con sus términos y derechos, así como las heredades que tenían en Trevijano (Soto de Cameros, La Rioja) a cambio del citado monasterio de San Agustín de Nalda, con sus tierras, y el de San Saturnino de Pavía, junto con su villa y todas sus pertenencias y derechos ${ }^{103}$.

Gracias a este intercambio, el monasterio de Albelda consolidó sus propiedades en el valle del Iregua, cediendo buena parte, si no todas las que tenía en el valle del Leza, incluido Pampaneto, al de San Prudencio de Monte Laturce que, debido a la influyente posición de Jimeno Fortuñones, continuó adquiriendo una importante expansión territorial en los valles de los ríos Leza, Jubera y Cidacos.

La realización del documento fue encargada por el obispo Munio, que lo confirmó bajo el reinado de Sancho Garcés IV, en Nájera y Pamplona ${ }^{104}$, junto a la confirmación del conde García, señor de Nájera y Calahorra ${ }^{105}$, Jimeno Fortuñones, de Meltria ${ }^{106}$ y ambos Cameros ${ }^{107}$, Lope López, de Marañón (Navarra) ${ }^{108}$ y Mirón,

101 Cantera Orive ubicó San Pelayo de Leza en Leza del Río Leza (La Rioja) aunque también cabría considerar la existencia del topónimo de San Pelayo situado a orillas del río Leza, en Ribafrecha (La Rioja), mientras no se confirme su ubicación. Por su parte, Cantera Montenegro aclaró que esta advocación correspondía al santo niño Pelayo, de origen hispano y martirizado en Córdoba (Andalucía), en 925. Cantera Montenegro no relacionó esta iglesia de San Pelayo con Pampaneto sino que identificó la propiedad del monasterio de San Pelayo al de Albelda, a finales del siglo XI. No obstante, la época del martirio de San Pelayo es un buen argumento para considerar que esta iglesia de San Pelayo tuvo que ser posterior a la reconquista definitiva del valle de Leza. CANTERA 1962, p. 334 y CANTERA 1985, pp. 48-49.

102 Seguramente, San Andrés también debió estar en el valle del río Leza, pero en el límite fronterizo con el término del monasterio albeldense, pues se recalca que sea quitada y abstrayda de nuestro [monasterio de Albelda] derecho y confirmada en el derecho de San Prudencio por todos los siglos de los siglos Amén. Esta aclaración, además, podría indicar la existencia de un conflicto territorial por la jurisdicción sobre dicha iglesia de San Andrés, al menos eclesiástica y quizá también civil. Margarita Cantera recogió la posibilidad de que haga referencia a la aldea de San Andrés de Cameros (Lumbreras, La Rioja), en la cuenca alta del río Iregua, al pie de la Sierra Cebollera y del puerto de Piqueras, en el cruce de las calzadas que desde las mansiones romanas de Vareia (Varea) y Barberiana (Murillo de Río Leza) con Numancia (Garray, Soria, Castilla y León). Sin embargo, la expresión junto a San Fructuoso parece indicar una mayor cercanía a Villanueva de San Prudencio que la ya alejada de San Andrés de Cameros. Particularmente, si se considera que entre ambas se encuentra San Román de Cameros y que ésta pudo también estar relacionada con Pampaneto. Además, Margarita Cantera cita la incorporación del monasterio de San Andrés, en 1100, al monasterio de San Millán de la Cogolla, con lo que éste pudo ser el que debió haber en San Andrés de Cameros, distinto del que hubo en Zenzano, junto a Villanueva de Pampaneto. CANTERA 1985, p. 47, PASCUAL y PASCUAL 1994, pp. 359-360 y RUBIO 1997, pp. 55-56.

103 GARCÍA 1992, n. 10.

104 Parece una anomalía ya que la cláusula correcta debería decir en Pamplona y Nájera, no en el orden contrario que aquí figura. VICUÑA 1971, p. 130.

105 Se trata del conde de Nájera, García Ordóñez el Crespo, que se casó en 1076 con la hermana de Sancho Garcés IV y que, además, fue tenente de la Calahorra castellana (¿1086?-1108) bajo el reinado de Alfonso VI el Bravo, que reinó en León (1065-1109) y en Castilla (1072-1109). Según Ubieto, Calahorra pasó a estar a su cargo entre 1081 y 1086, poseyéndola junto con Nájera y Grañón (La Rioja) hasta su muerte. LEZA 1959, pp. 22-23, UBIETO 1969, p. 225, VICUÑA 1971, pp. 142-143, CANAL 1997, pp. 756, 760 y 762 y TORRES 1999, pp. 103-105.

106 Inicialmente Ildefonso Rodríguez ubicó esta tenencia cerca de Logroño (La Rioja), concretamente en el término de Val de Metria de Viguera, en el valle del Iregua, y consideró que esta tenencia ejercía su jurisdicción sobre este valle y el del río Leza. Además, constató que, a principios del siglo XI, 
prior del monasterio de San Martín de Albelda ${ }^{109}$, junto a toda su congregación. Sin embargo, las inconsistencias de su escatocolo, particularmente en lo que se refiere a la demasiado temprana aparición del conde García Ordóñez y del señor Lope López, son una clara demostración de la reconstrucción a la que fue sometido este documento, más de una década después de cuando se supone que está datado, o incluso más tarde aún, si es que fue rehecho o inventado con posterioridad al magnicidio acaecido en el barranco de Peñalén (Funes), en 1076.

No obstante, todo parece indicar que Pampaneto se integró entre las propiedades del monasterio de San Prudencio de Monte Laturce, siendo una de las pruebas más evidentes el que Villanueva de Pampaneto acabó siendo conocida como Villanueva de San Prudencio, cuyo topónimo aún se conserva ${ }^{110}$.

\section{LAS ÚLTIMAS REFERENCIAS ACERCA DE PAMPANETO}

A pesar de haber cedido Pampaneto y otras posesiones al monasterio de San Prudencio de Monte Laturce, el monasterio albeldense todavía conservó allí algunas propiedades bastante tiempo después, pues de ello hay constancia hacia el año 1100.

Concretamente, figura que entre las posesiones que entonces tenía el monasterio albeldense en Jubera se encontraba un linar en Pampaneto, junto al soto de lonti, y varias viñas en el plano de Pampaneto que había bajo los Ortiellos, así como una pieza en Villanova y otra en San Saturnino ${ }^{111}$. Seguramente, además, estas dos últimas propiedades hagan referencia a Villanueva de San Prudencio y al monasterio de San Saturnino de Pavia, respectivamente. De modo que también se pueden contar entre las últimas referencias conocidas acerca de Pampaneto.

\footnotetext{
la ostentaba Fortún Ochoaz y después su hijo Jimeno Fortuñones. Pascual concluyó que no existían restos de suficiente entidad que atestiguasen la posible ubicación del castillo de Viguera en Valdemetria (Viguera) aunque sin relacionar estas ruinas con las de la posible tenencia de Meltria. Sin embargo, Peterson recogió esta cita y, siguiendo a Ildefonso Rodríguez, ubicó allí esta tenencia. Previamente, Pescador ubicó erróneamente la tenencia de Meltria en el monte logroñés de Cantabria, en la margen izquierda del Ebro, debido a que Fortún Ochoa también figura ocupando esta tenencia riojana. RODRÍGUEZ 1975, pp. 105 y 108, RODRÍGUEZ 1992, p. 360, PASCUAL 1994, p. 345, FERNÁNDEZ DE LA PRADILLA 1994, p. 42, PESCADOR 1999, pp. 121, 126 y 130, GRANADO y FERNÁNDEZ DE LA PRADILLA 1999, pp. 23 y 27, y PETERSON 2005, pp. 19-20.

107 Jimeno Fortuñones fue tenente de Meltria entre 1056 y 1068, así como de Cameros, entre 1056 y 1092, según Ubieto que, desafortunadamente, lo identificó con su casi homónimo Jimeno Fortuñones de Lehet, en vez de hacerlo correctamente con el citado hijo de Fortún Ochoaz. UBIETO 1973, pp. 236237 y FERNÁNDEZ DE LA PRADILLA 1994, p. 42.

108 Lope López figura a cargo de Marañón entre 1082 y junio de 1107. Ubieto no recogió noticias suyas como tenente con anterioridad a esta primera fecha. UBIETO 1973, p. 247.

109 Fortín Pérez de Ciriza constató la presencia del prior albeldense, Vidal entre 1062 y 1082 . Mientras que Cantera Orive señaló el priorato de Mirón bajo el episcopado de Pedro de Nazar (1089-1108), constatando que nunca figuró como abad. Aunque después SÁINZ lo consideró como tal. CANTERA 1961a, pp. 81-82, SÁINZ 1994, pp. 174, 247-264 y 277-287, y FORTÚN 2005, p. 225.

110 Villanueva de San Prudencio, aldea de Zenzano. GONZÁLEZ 1987, p. 600.

111 UBIETO 1981, n. 66.
} 


\section{LA ANTIGÜEDAD DE LAS INTERPOLACIONES DE LOS DOCUMENTOS DE PAMPANETO}

Mirón, prior del monasterio albeldense, compuso la primera relación o inventario de este monasterio en una fecha indeterminada, pero que es posterior al año $1094^{112}$ y anterior a $1108^{113}$. En él se cita que el rey García Sánchez III dio al monasterio de San Martín de Albelda el de Pampaneto con sus pertenencias: Villanova y San Pelayo de Leza, con sus tierras, viñas y molinos, así como una heredad que estaba en Lagunilla de Jubera, otra que había en Viloria, el monasteriolo de San Andrés, situado junto a Pampaneto, y muchas heredades que había en Trevijano.

Ubieto identificó todas estas propiedades albeldenses con el documento $\mathrm{n}$. $36^{114}$. Efectivamente, en éste y en el siguiente documento del cartulario albeldense se hace referencia al intercambio de Pampaneto y su villa de Villanova por Covela. Sin embargo, en ellos no se menciona San Pelayo de Leza como una de las propiedades que estaban incluidas entonces entre las de Pampaneto y que, de haber sido así, debería haber figurado en el documento n. 36.

La constancia de que el monasterio de San Pelayo de Leza se incluyó entre las propiedades de Pampaneto que el monasterio albeldense cedió al de San Prudencio de Monte Laturce, hace plausible que los documentos de ambos intercambios, a pesar de estar manipulados, daten de antes de 1094 y que incluso puede que para cuando los consultó y registró Mirón ya no se tratase de los originales. A no ser que fuese precisamente él quien los alteró o recompuso justo antes de indexarlos en su catálogo. Lo mismo se puede decir de la referencia que este prior albeldense hizo a las múltiples heredades que tenían en Trevijano, al monasterio de San Andrés y al dato de que éste se encontraba junto a Pampaneto, así como al intercambio de Pampaneto y otras heredades por Covela. De modo que se debe concluir que las manipulaciones son anteriores o contemporáneas al registro de Mirón y, por tanto, que ya existían a finales del siglo XI.

\section{CONCLUSIONES}

La revisión de los escasos documentos relativos al monasterio de Pampaneto han puesto de manifiesto su proceso expansivo e influencia en la repoblación y organización del valle del río Leza, de la que ya hay constancia entre mediados del siglo X y el momento de la ascensión al trono de Sancho Garcés III. Durante este período y el del reinado de su hijo y heredero, García Sánchez III, hasta mediados del siglo XI, Pampaneto alcanzó su máximo esplendor, proyectando su labor de or-

112 Cantera Orive lo dató el año 1094 poco más o menos. Sin embargo, no puede ser anterior a 1094 ya que, como expuso Ubieto, en el inventario de Mirón figura una referencia a un documento de dicho año. CANTERA 1950c, p. 510, UBIETO 1981, n. 68 y SÁINZ 1981, n. 10.

${ }_{113}$ No puede ser posterior a la muerte del obispo Pedro. UBIETO 1981, n. 68 y SÁINZ 1981, n. 10.

114 UBIETO 1981, p. 90. 
Pampaneto, el monasterio de San Fructuoso y su influencia en la organización...

ganización y apoyo en la primera línea de retaguardia que propició la reconquista definitiva de Calahorra y el definitivo avance de la frontera entre la margen oriental del valle del Cidacos y la occidental del Alhama.

La incorporación de Pampaneto al conjunto de propiedades del monasterio de San Martín de Tours de Albelda había oscurecido su labor anterior en esta región fronteriza del reino de Pamplona. Del mismo modo que su posterior y definitiva incorporación al monasterio de San Prudencio de Monte Laturce casi lo habían hecho desparecer de la historiografía, no sólo por haber perdido su independencia al ser absorbido por estos dos importantes monasterios riojanos, sino porque también éstos están pendientes de un merecido estudio en profundidad, como también lo está el conocimiento de la historia de la Rioja Media y Baja, así como el de la Ribera de Navarra en la Edad Media.

Por último, cabe señalar que la revisión de su ubicación, así como la de alguna de las principales propiedades con las que le asocia la documentación que se ha conservado acerca de este monasterio de San Fructuoso, indirectamente, también ha llevado a la localización del posible coto redondo que pudo tener la villa altomedieval de Covela o Cuvilla. Así como a la relación entre sus límites o los de diversas propiedades y villas situadas en la zona del último tramo del río Leza y la principal calzada romana a su paso por la mansio Barberiana, transformada ya, en el siglo XI, en una villa antigua, sobre la que también se han aportado detalles acerca de su localización, así como de la del puente romano sobre el río Leza, o sobre la existencia de una presa romana o, al menos, de época medieval, situada cerca de la desembocadura de dicho río.

\section{BIBLIOGRAFÍA}

Abad León, Felipe (1999), «Expansión de la Vida Eremítica y Monástica en La Rioja», en Antigüedad y Cristianismo, n. 16, ejemplar dedicado a: Los columbarios de la Rioja, Murcia, pp. 285-312.

Alonso Fernández, CARmen - Jiménez EcheVerríA, Javier (2008), «La «Vía Romana de Italia a Hispania» a su Paso por la Comunidad Autónoma de La Rioja», en Berceo, n. 154, Logroño, pp. 191-226.

Alonso García, Daniel (1957), «Apuntes Históricos de la Villa de Alcanadre (Continuación)», en Berceo, n. 43, Logroño, pp. 199-214.

- (1994), «Historia de la Villa de Alcanadre y de su Término de Aradón (La Rioja): Relaciones con la Historia de España», Madrid.

AntoñAnzAs Subero, Asunción (2003), «La Iglesia de Velilla de Aracanta: ¿Realidad o Invención Historiográfica?», en Iberia, n. 6, Logroño, pp. 111-142.

Cadiñanos BARDeCI, Inocencio (1982), «Agoncillo y su Fortaleza», en Berceo, n. 103, Logroño, pp. 113124.

- (1990), «Agoncillo y su Fortaleza», en Brocar, n. 16, Logroño, pp. 61-70.

Canal Sánchez-Pagín, José M. a (1997), “El Conde García Ordóñez, Rival del Cid Campeador, su Familia, sus servicios a Alfonso Vl», en Anuario de Estudios Medievales, n. 27, t. 2, Barcelona, pp. 749773.

Canellas lópez, Ángel (1979), “García Sánchez, Rey de Pamplona (1035-1054)», en Cuadernos de Investigación: Geografía e Historia, t. 5, f. 2, Logroño, pp. 135-156.

Cantera Montenegro, Margarita (1985), "Advocaciones Religiosas en la Rioja Medieval», en Anuario de Estudios Medievales. Estudios dedicados a la memoria de D. Claudio Sánchez Albornoz, Barcelona, pp. 39-61. 
- (2005). «La ciudad de Nájera en tiempos del rey García», en García Sánchez III »el de Nájera», un rey y un reino en la Europa del siglo XI: XV Semana de Estudios Medievales, Nájera, Tricio y San Millán de la Cogolla. Logroño, pp. 39-72.

Cantera Orive, Julí́n (1944), «La Batalla de Clavijo y Aparición en ella de Nuestro Santo Patrón Santiago: Undécimo Centenario, 23 Mayo 844-23 Mayo 1944», Vitoria.

- (1950a), «El Primer Siglo del Monasterio de Albelda (Logroño, 924 - 1024 )», en Berceo, n. 14, Logroño, pp. 13-24.

- (1950b), «El Primer Siglo del Monasterio de Albelda (Logroño, 924 - 1024 ) (Continuación)», en Berceo, n. 15, Logroño, pp. 313-326.

- (1950c), «Primer Siglo del Monasterio de Albelda (Logroño, 924 - 1024 ) (Continuación)», en Berceo, n. 16, Logroño, pp. 509-521.

- (1951a), «El Primer Siglo del Monasterio de Albelda (Logroño, 924 - 1024 ) (Continuación)», en Berceo, n. 19, Logroño, pp. 176-186.

- (1951b), «El Primer Siglo del Monasterio de Albelda (Logroño, 924 - 1024 )», en Berceo, n. 21, Logroño, pp. 531-542.

- (1952), «El Primer Siglo del Monasterio de Albelda (Logroño, 924 - 1024 ) (Continuación)», en Berceo, n. 23, Logroño, pp. 293-308.

- (1958), “Un Cartulario de Santa María la Real de Nájera, del Año 1209», en Berceo, n. 48, Logroño, pp. 305-320.

- (1961a), «El Primer Siglo del Monasterio de Albelda (Logroño, 924 - 1024 )», en Berceo, n. 58, Logroño, pp. 81-98.

- (1961b), «El Primer Siglo del Monasterio de Albelda (Logroño, 924 - 1024 )», en Berceo, n. 61, Logroño, pp. 437-448.

- (1962), «El Primer Siglo del Monasterio de Albelda (Logroño, 924 - 1024 )», en Berceo, n. 64, Logroño, pp. 327-342.

- (1964a), «Buscando a Atilana», en Berceo, n. 71, Logroño, pp. 133-150.

- (1964b), «Atilana - Ventas de Valpierre», en Berceo, n. 73, Logroño, pp. 373-386.

Castellanos García, Santiago (1995), «Problemas Metodológicos en la Investigación de la Ocupación del Territorio durante la Antigüedad Tardía: El Caso del Alto Ebro y la Aportación de la «Vita Sancti Aemiliani»», en Brocar, n. 19, Logroño, pp. 27-48.

DutTon, BriAn (1980), «Berceo y la Rioja Medieval: Apuntes Botánicos», en Berceo, n. 98, Logroño, pp. 3-30.

Espinosa RUIz, Urbano (1994), «Vareia en el Orbe Romano», en Vareia en el Universo Romano de la Sumisión a la Integración, en Historia de la Ciudad de Logroño, t. 1, coordinado por Urbano Espinosa Ruiz, Logroño, pp. 97-300.

- (2003), «El Enclave Parpalines de la Vita Sancti Aemiliani; Espacio Rural y Aristocracia en Época Visigoda», en Iberia, n. 6, Logroño, pp. 79-109.

- (2006), «La Iglesia Tardoantigua de Parpalinas (Pipaona de Ocón, La Rioja). Campaña Arqueológica de 2005", en Antigüedad Cristiana, n. XXIII, Murcia, pp. 309-322.

Fernández de la Pradilla Mayoral, María Concepción (1991), «El Reino de Nájera (1035-1076). (Población, Economía, Sociedad y Poder)", en Biblioteca de estudios Riojanos, n. 81, Logroño.

- (1994), "La Articulación del Poder Pamplonés en el Espacio Riojano», en Historia de la Ciudad de Logroño, t. II (Edad Media), Logroño, pp. 35-46.

ForTún PÉREZ DE CIRIZA, LUIS JAVIER (2005), «Monjes y Obispos: La Iglesia en el Reinado de García Sánchez III el de Nájera», en García Sánchez III "el de Nájera». Un Rey y un Reino en la Europa del Siglo XI, XV Semana de Estudios Medievales. Nájera, Tricio y San Millán de la Cogolla 2004, Logroño, pp. 191-252.

García de Cortázar Ruíz de Aguirre, José Ángel (1985), «La Rioja Alta en el Siglo X. Un Ensayo de Análisis Cartográfico Sobre los Comienzos de la Ocupación y Explotación Cristiana del Territorio», en Príncipe de Viana, n. 132-133, Pamplona, pp. 309-336.

García Turza, Francisco Javier (1989), «El Monasterio de San Prudencio de Monte Laturce (Siglos XXII)», en Espacio, Tiempo y Forma, Serie III, t. 2, Madrid, pp. 137-160.

- (1992), «Documentación Medieval del Monasterio de San Prudencio de Monte Laturce (Siglos XXV)», en Biblioteca de Temas Riojanos, n. 85, Logroño.

- (1993), "Las Aldeas de la Rioja Medieval: El Ejemplo de Villanueva», en II Semana de Estudios Medievales, Nájera 5 al 9 de agosto de 1991 coordinada por José Ignacio de la Iglesia Duarte, reedición de 2001, Logroño, pp. 233-241.

GonzÁlez, TomÁs (1833), "Colección de Privilegios, Franquezas, Exenciones y Fueros, Concedidos Á Varios Pueblos y Corporaciones de la Corona de Castilla, Copiados de Orden de S. M., de los Registros 
Pampaneto, el monasterio de San Fructuoso y su influencia en la organización...

del Real Archivo de Simancas. Sirve de Continuación a la Colección de Documentos Concernientes a las Provincias Vascongadas", t. VI, Imprenta de D. M. de Burgos.

González Blanco, Antonino (1987), "Diccionario de Toponimia Actual de La Rioja», Murcia.

GoÑI GaZTAMBIDE, José (1979), «Historia de los Obispos de Pamplona, Siglos IV-XIIl», t. I, Pamplona.

Govantes Fernández-Angulo, Ángel Casimiro (1846), "Diccionario Geográfico-Histórico de España, por la Real Academia de la Historia. Sección II. Comprende La Rioja o Toda la Provincia de Logroño y Algunos Pueblos de la de Burgos», Imprenta de Viuda de Jordán e hijos, Burgos.

Granado Hijelmo, Ignacio - Fernández de la PRAdilla Mayoral, María Concepción (1999), "Introducción Histórica al Señorío de los Cameros", en Lafuente Urién, AránZaZu - Granado HiJelmo, Ignacio Fernández de la pradilla Mayoral, María Concepción - García Aser, Rosario - Gallo león, FranCISco JosÉ, "El Señorío de los Cameros: Introducción Histórica e Inventario de su Archivo», Logroño.

GuRRUCHAGA, ILDEFONSO (2003), «Localización de Algunas Ciudades Várdulas Citadas por Mela y Ptolomeo", en VII Congreso de estudios Vascos: Biarritz 1948, San Sebastián, pp. 217-221.

Hernández Vera, José Antonio - Ariño Gil, Enrique - Martínez Torrecilla, José Manuel - Núñez MarCÉn, JuLIo (1999), «La Presa y el Ninfeo del Sotillo (Alfaro, La Rioja): Un Conjunto Monumental en la Vía De Italia in Hispanias", en Zephyrus, n. 52, Salamanca, pp. 239-260.

Jimeno Aranguren, Roldán - Pescador Medrano, Aitor (2003) «Colección Documental de Sancho Garcés III, el Mayor, Rey de Pamplona (1004-1035)", Pamplona.

LaCARRA de Miguel, José María (1965), “Colección Diplomática de Irache», en Fuentes para la Historia del Pirineo II, v. I (958-1222), Pamplona.

- (1972), «Historia Política del Reino de Navarra desde sus Orígenes hasta su Incorporación a CastiIla», t. I, Pamplona.

ladero Quesada, Miguel Ángel - Mattoso, José - Martín Duque, Ángel J. - Udina Martorell, Federico - Fortún Pérez de Ciriza, Luis Javier - Sesma Muñoz, José Ángel (1998), «La Reconquista y el Proceso de Diferenciación Política (1035-1217)», en Historia de España. Menéndez Pidal, dirigida por José María Jover Zamora, coordinación e introducción de Miguel Ángel Ladero Quesada, Madrid, pp. 239-279.

LÁzaro Ruiz, Mercedes (1997), «El Monasterio de San Martín de Albelda: Estrategias en la Ocupación del Territorio y Valoración Socioeconómica (925-1094)», en VII Semana de Estudios Medievales: Nájera, 29 de julio al 2 de agosto de 1996, coordinado por José Ignacio de la Iglesia Duarte, 1997, Logroño, pp. 353-384.

LezA, Jesús (1959), "Los Lope Díaz de Haro, Señores de Vizcaya y los Señores de los Cameros», en Zephyrus, n. 52, Salamanca, pp. 239-260.

Llorente González, JuAn Antonio (1807), «Noticias Históricas de las Tres Provincias Vascongadas: Álava, Guipúzcoa y Vizcaya. Parte III. Apéndice o Colección Diplomática", tomo III, Imprenta Real, Madrid.

- (1808), «Noticias Históricas de las Tres Provincias Vascongadas: Álava, Guipúzcoa y Vizcaya. Parte III. Apéndice o Colección Diplomática», tomo IV, Imprenta Real, Madrid.

Mañaricúa Nuere, Andrés (1964), “Obispados en Álava, Guipuzcoa y Vizcaya hasta la Erección de la Diócesis de Vtoria (28 de Abril de 1862)», en Victoriensia, n. 19, Vitoria.

Martín Duque, Ángel (2007), «Sancho III el Mayor de Pamplona. El Rey y su Reino (1004-1035)», Pamplona.

Martínez Díez, Gonzalo (1984), "Los Obispados de la Castilla Condal Hasta la Consolidación del Obispado de Oca en Burgos en el Concilio de Burgos (1088)», en El Factor Religioso en la Formación de Castilla, Burgos, pp. 87-164.

- (1987), «Pueblos y Alfoces Burgaleses de la Repoblación», Valladolid.

- (2007), «Sancho III el Mayor», Madrid.

MORET, JOSÉ (1766), "Anales del Reino de Navarra», t. III (Libros 11-14), edición anotada e índices dirigida por Susana Herreros Lopetegui (1989), Pamplona.

Oca Merino, Esteban (1913): «Recuerdos de Cameros. Apuntes de Geografía e Historia de la Región, y de los Hijos Distinguidos de la Misma», Logroño.

Olabuenaga Ornes, Mitxel (2001): “Organización Territorial, Política y Administrativa de la Anteiglesia de Barakaldo. Las Ordenanzas de 1614», en Arbela. Baracaldo, pp. 24-34.

Pascual Mayoral, María del Pilar (1994) «Puente Caneco y Castillo de Viguera", en IV Semana de Estudios Medievales. Nájera, del 2 al 6 de Agosto de 1993, Logroño, pp. 341-350.

Pascual Mayoral, María del Pilar - Pascual González, Hilario (1994), «La Mansión de Barbariana: Se Precisa su Localización en el Yacimiento Romano Existente en el Topónimo «Barbarés» (Murillo del Río Leza) ', en Antigüedad y Cristianismo, n. 11, ejemplar dedicado a Sidonio Apolinar, Humanista de la Antigüedad Tardía: Su Correspondencia, Murcia, pp. 327-397. 
Pascual Mayoral, María del Pilar - Pascual González, Hilario - García Ruiz, Pedro, (2005) «Torrillas: Una Villa Entre Monarcas y Monasterios Navarros y Castellanos. Logroño (La Rioja)», en Altza, n. VIII, Altza, pp. 147-161.

Peña de San José, Joaquín (1959), «Documentos del Convento de San Millán de la Cogolla, en los que Figura don Gonzalo de Berceo», en Berceo, n. 50, Logroño, pp. 79-94.

Pescador Medrano, Aitor (1999), «Tenentes y Tenencias del Reino de Pamplona en Álava, Gupúzcoa, La Rioja y Castilla (1004-1076)», en Vasconia, San Sebastián, pp. 107-144.

Peterson, David (2005), «De Divisione Regno», en Brocar, n. 29, Logroño, pp. 7-26.

Ramírez Martínez, José Manuel (1973), «Edificios Religiosos de Murillo de Río Leza», en Berceo, n. 84, Logroño, pp. 5-36.

Riu Riu, Manuel (1989), «Poncio de Tabernoles, Obispo de Oviedo», en Espacio, Tiempo y Forma, Serie III, Historia Medieval, n. 4, Madrid, pp. 425-436.

Rodríguez Rodríguez de LAMA, ILdefonso (1975), «La Tenencia de Meltria en el Siglo Xl», en Berceo, $\mathrm{n}$. 88, Logroño, pp. 105-108.

Rodríguez Rodríguez de Lama, Ildefonso (1992), “Colección Diplomática Medieval de la Rioja (923-

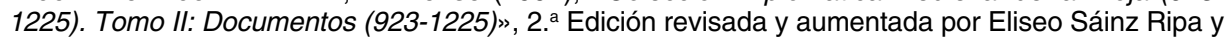
Ciriaco López de Silanes, Logroño.

Rubio Martínez, Juan Carlos (1997), «Una Estela Funeraria Romana en San Andres de Cameros, La Rioja», en Faventia, n. 19, f. 1, Barcelona, pp. 55-63.

Ruíz-NavarRo Pérez, Julián (1972), «El Castillo de Clavijo», en Berceo, n. 83, Logroño, pp. 151-157.

- (1990), «El Castillo de Clavijo», en Brocar, n. 16, Logroño, pp. 51-60.

Sáenz Preciado, Jesús Carlos (1994), «Prospecciones Arqueológicas en el Término de «El Juncal de Velilla» (Agoncillo, La Rioja)», en Estrato, n. 6, Logroño, pp. 76-82.

SÁINZ RIPA, ELISEO (1981), «Colección Diplomática de las Colegiatas de Albelda y Logroño (T. I: 9241399)», Logroño.

- (1994), "Sedes Episcopales de la Rioja», t. I, Siglos IV- XIII, Logroño.

Torres SeVilla-Quiñones de León, Margarita Cecilia (1999), «Linajes Nobiliarios de León y Castilla. Siglos IX-XIII», Salamanca.

Ubieto Arteta, Agustín (1969), «Notas Sobre los «Tenentes» de Calahorra en los Siglos XI y XII», en Príncipe de Viana, n. 116-117, Pamplona, pp. 221-231.

- (1973), «Los Tenentes en Aragón y Navarra en los Siglos XI y XII», Valencia.

Ubieto Arteta, Antonio (1963), «Cartulario de San Juan de la Peña. Volumen Il», en Textos Medievales, n. 9, Valencia.

- (1976), «Cartulario de San Millán de la Cogolla (759-1076)», Valencia.

- (1981), "Cartulario de Albelda», en Textos Medievales, I, Zaragoza.

Vicuña Ruiz, Francisco Javier (1971), «La Rioja, Tierra de Contacto entre los Reinos Hispanos», en Berceo, n. 81, Logroño, pp. 127-148. 